\title{
Effect of island overlap on edge localized mode suppression by resonant magnetic perturbations in DIII-D
}

M. E. Fenstermacher, T. E. Evans, T. H. Osborne, M. J. Schaffer, M. P. Aldan, J. S. deGrassie, P. Gohil, I. Joseph, R. A. Moyer, P. B. Snyder, R. J. Groebner, M. Jakubowski, A. W. Leonard, O. Schmitz, and the DIII-D Team

Citation: Physics of Plasmas 15, 056122 (2008); doi: 10.1063/1.2901064

View online: https://doi.org/10.1063/1.2901064

View Table of Contents: http://aip.scitation.org/toc/php/15/5

Published by the American Institute of Physics

\section{Articles you may be interested in}

Edge-localized-modes in tokamaks

Physics of Plasmas 21, 090501 (2014); 10.1063/1.4894742

Edge localized modes and the pedestal: A model based on coupled peeling-ballooning modes

Physics of Plasmas 9, 2037 (2002); 10.1063/1.1449463

Calculations of two-fluid linear response to non-axisymmetric fields in tokamaks

Physics of Plasmas 19, 056105 (2012); 10.1063/1.3694657

Comparative investigation of ELM control based on toroidal modelling of plasma response to RMP fields Physics of Plasmas 24, 056111 (2017); 10.1063/1.4978884

Validation of the model for ELM suppression with 3D magnetic fields using low torque ITER baseline scenario discharges in DIII-D

Physics of Plasmas 24, 102501 (2017); 10.1063/1.5000276

The EPED pedestal model and edge localized mode-suppressed regimes: Studies of quiescent $\mathrm{H}$-mode and development of a model for edge localized mode suppression via resonant magnetic perturbations

Physics of Plasmas 19, 056115 (2012); 10.1063/1.3699623

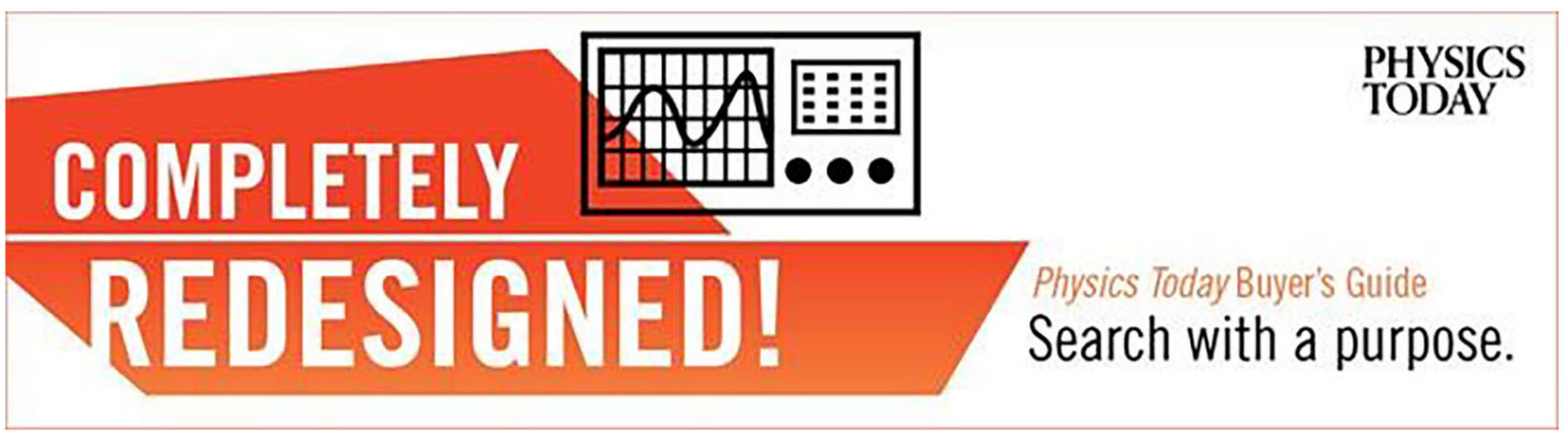




\title{
Effect of island overlap on edge localized mode suppression by resonant magnetic perturbations in DIII- $D^{a)}$
}

\author{
M. E. Fenstermacher, ${ }^{1, b)}$ T. E. Evans, ${ }^{2}$ T. H. Osborne, ${ }^{2}$ M. J. Schaffer, ${ }^{2}$ M. P. Aldan, ${ }^{3}$ \\ J. S. deGrassie, ${ }^{2}$ P. Gohil, ${ }^{2}$ I. Joseph, ${ }^{4}$ R. A. Moyer, ${ }^{4}$ P. B. Snyder, ${ }^{2}$ R. J. Groebner, ${ }^{2}$ \\ M. Jakubowski, ${ }^{5}$ A. W. Leonard, ${ }^{2}$ O. Schmitz, ${ }^{5}$ and the DIII-D Team \\ ${ }^{1}$ Lawrence Livermore National Laboratory, Livermore, California 94550, USA \\ ${ }^{2}$ General Atomics, P.O. Box 85608, San Diego, California 92186, USA \\ ${ }^{3}$ University of California-Berkeley, Berkeley, California 94720, USA \\ ${ }^{4}$ University of California-San Diego, La Jolla, California 92093, USA \\ ${ }^{5}$ Institut fur Plasmaphysik, FZ-Jülich Euratom Association, 52425 Jülich, Germany
}

(Received 15 November 2007; accepted 11 February 2008; published online 8 May 2008)

\begin{abstract}
Recent DIII-D [J. L. Luxon et al., Nucl. Fusion 43, 1813 (2003)] experiments show a correlation between the extent of overlap of magnetic islands induced in the edge plasma by perturbation coils and complete suppression of Type-I edge localized modes (ELMs) in plasmas with ITER-like electron pedestal collisionality $\nu_{e}^{*} \sim 0.1$, flux surface shape and low edge safety factor $\left(q_{95} \approx 3.6\right)$. With fixed amplitude $n=3$ resonant magnetic perturbation (RMP), ELM suppression is obtained only in a finite window in the edge safety factor $\left(q_{95}\right)$ consistent with maximizing the resonant component of the applied helical field. ELM suppression is obtained over an increasing range of $q_{95}$ by either increasing the $n=3$ RMP strength, or by adding $n=1$ perturbations to "fill in" gaps between islands across the edge plasma. The suppression of Type-I ELMs correlates with a minimum width of the edge region having magnetic islands with Chirikov parameter $>1.0$, based on vacuum calculations of RMP mode components excluding the plasma response or rotational shielding. The fraction of vacuum magnetic field lines that are lost from the plasma, with connection length to the divertor targets comparable to an electron-ion collisional mean free path, increases throughout the island overlap region in the ELM suppressed case compared with the ELMing case. (C) 2008 American Institute of Physics. [DOI: 10.1063/1.2901064]
\end{abstract}

\section{INTRODUCTION}

In the high confinement mode (H-mode) tokamak plasmas needed for sufficient energy gain to extrapolate to attractive reactor scenarios, the plasma edge produces bursts of particles and energy, due to MHD instabilities driven by the steep H-mode edge pressure and current gradients, that are large enough to produce significant erosion of plasma material interaction surfaces. ${ }^{1}$ These edge localized modes (ELMs) are nonlinear explosive instabilities ${ }^{2}$ that can carry on the order of $20 \%$ of the edge pedestal stored energy from the closed, well confined flux surfaces onto open field lines that intersect material surfaces. ${ }^{3}$ Extrapolations of ELMs to the International Thermonuclear Experimental Reactor (ITER) (Ref. 4) indicate that the fractional energy loss that can be tolerated without excessive erosion of the target surfaces must be reduced from $20 \%$ to the order of $1 \%-5 \%$ of the pedestal plasma stored energy. ${ }^{5}$ The viability of future tokamak reactors operating in $\mathrm{H}$-mode requires development of techniques to reliably produce this reduction in the ELM heat and particle fluxes while retaining the high-energy confinement of the $\mathrm{H}$-mode core plasma.

This paper presents analysis of plasmas in which resonant magnetic perturbations (RMPs) in the plasma edge in DIII-D not only reduce the size of, but can completely sup-

\footnotetext{
${ }^{a)}$ Paper BI1 2, Bull. Am. Phys. Soc. 52, 21 (2007).

${ }^{b)}$ Invited speaker.
}

press the largest Type-I ELMs, ${ }^{6,7}$ exceeding reduction requirements for future devices. The RMPs are generated by currents in external perturbation coils. To enable straightforward extrapolation to ITER, discharges in this study have a lower single-null (LSN) ITER similar shape (ISS) and pedestal electron collisionality ${ }^{8}$ similar to ITER, $\nu_{e}^{*} \sim 0.1$.

The recent DIII-D experiments achieved complete suppression of Type-I ELMs at low collisionality in the ISS configuration for a range of plasma conditions. ${ }^{9,10}$ ELM suppression was also seen previously in low collisionality plasmas with a lower triangularity shape ${ }^{11-14}$ and in higher collisionality plasmas with a more nearly double-null shape. ${ }^{15-19}$ The present experiments extend the range of parameter scans of the previous work, in particular to combinations of $n=3$ RMPs with applied $n=1$ fields, in an attempt to test a simple picture of the dependence of ELM suppression on the degree of magnetic island overlap in the plasma edge.

Application of RMPs is just one of many techniques under investigation for ELM control. Other techniques include pellet ELM pacing by the ASDEX-U group, ${ }^{20}$ ELM pacing using temporal magnetic triggering by the TCV (Ref. 21) and ASDEX-U (Ref. 22) groups, various small ELM regimes at JT-60U, ${ }^{23,24}$ ASDEX-U, ${ }^{25}$ NSTX, ${ }^{26,27} \mathrm{JET}^{28}$ C-Mod, ${ }^{29}$ JFT-2M, ${ }^{30,31}$ Compass-D (Ref. 32) and DIII-D, ${ }^{33}$ and ELM-free operation in the QH-mode. ${ }^{34-39}$ Pioneering work on the effect of edge stochastic fields in circular limited plasmas was done by the TEXT group, ${ }^{40-43}$ by the Tore- 
Supra group (Refs. 44 and 45, and references therein), and by the TEXTOR group. ${ }^{46-48}$ Summaries of work on stochastic magnetic fields in fusion devices can be found in Refs. 49 and 50. There is also recent work with $n=1$ RMP fields at $\mathrm{JET}^{51}$

This paper is organized as follows. A description of the experimental conditions and parameter scans is given in Sec. II. The experimental results are given in Sec. III in the context of both the peeling-ballooning stability analysis of the ELMs (Ref. 52) and a simple picture in which the width of the region with good overlap of magnetic islands in the edge plasma, produced by the RMP coil currents, correlates with the achievement of the necessary reduction in ELM magnitude. In these experiments, the region of island overlap was changed by varying a number of different factors including the strength of the applied perturbation fields and the magnetic geometry in the edge plasma. A discussion of the experimental results including a comparison with theoretical expectations is given in Sec. IV. Conclusions and plans for future studies are presented in Sec. V.

\section{DESCRIPTION OF EXPERIMENTS}

For the experiments reported in this paper the plasmas had an ISS and divertor pumping to control the plasma density so that the pedestal electron collisionality was close to the value expected in ITER, $\nu_{e}^{*} \sim 0.1$. Since the edge stability has a strong dependence on both shape and collisionality (through the bootstrap current) the interpretation of the applicability of the RMP ELM suppression technique to ITER is more straightforward with these two parameters matched to the ITER values. The $2 \mathrm{D}$ equilibrium reconstruction of an ISS plasma [Fig. 1(a)] shows that the outer strike-point is in the optimal pumping position for good density control using the DIII-D lower outer cryopump, with lower triangularity $\delta_{\text {lower }}=0.67$, upper triangularity $\delta_{\text {upper }}=0.33$, and elongation $\kappa=1.8$. For reference, the ITER scenario 2 shape parameters are $\delta_{\text {lower }}=0.60, \delta_{\text {upper }}=0.43$, and $\kappa=1.8{ }^{4}$ The ISS plasmas were typically run with plasma current $I_{p}=1.65 \mathrm{MA}$, toroidal field $B_{T}=1.9 \mathrm{~T}$ (with scans in the range $I_{p}=1.4-1.7 \mathrm{MA}$ and $\left.B_{T}=1.75-2.10 \mathrm{~T}\right)$ and injected neutral beam power $P_{\text {inj }}=7-10 \mathrm{MW}$, giving normalized beta $\beta_{N}=\beta /\left(I_{p} / a B_{T}\right)=1.7-2.4$, where $a$ is the minor radius of the plasma and $\beta$ is the ratio of plasma pressure to magnetic field pressure. Time histories of a typical discharge (Fig. 2) show the suppression of the Type-I ELMs within $600 \mathrm{~ms}$ after the $n=3$ RMP from the I-coil is turned on, similar to results obtained with a lower triangularity shape. ${ }^{11-14}$

The spectrum of helical magnetic field perturbations used in these experiments included $n=3$ components from the DIII-D internal coil (I-coil), $n=1$ components from the DIII-D external error field correction coil (C-coil) and residual $n=1,2$, and 3 field errors from the DIII-D equilibrium field coils. The configuration of the coils [Fig. 1(b)] includes six toroidal C-coils outside the toroidal field (TF) and equilibrium field (EF) coils, and two rows of six I-coils mounted on the inside of the vacuum vessel inside both the TF and EF coils. The I-coils for these experiments were configured for

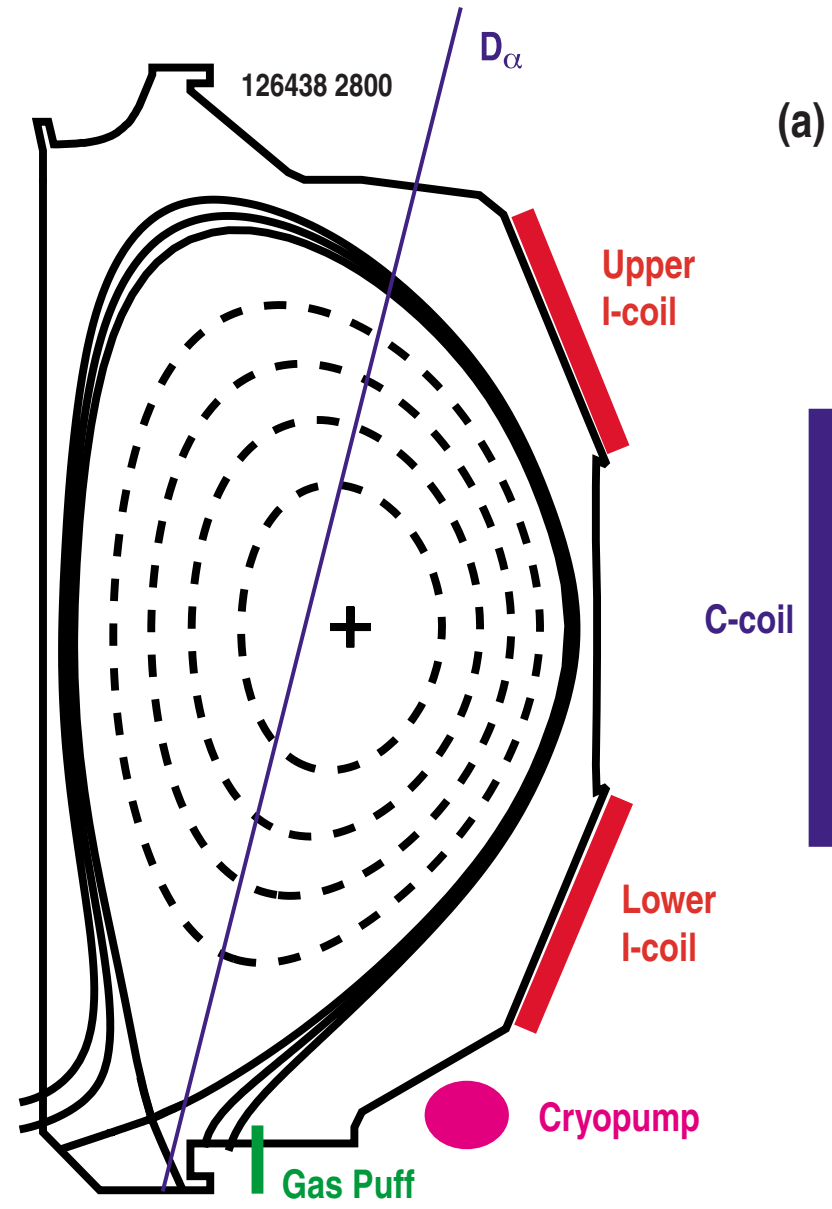

(b)

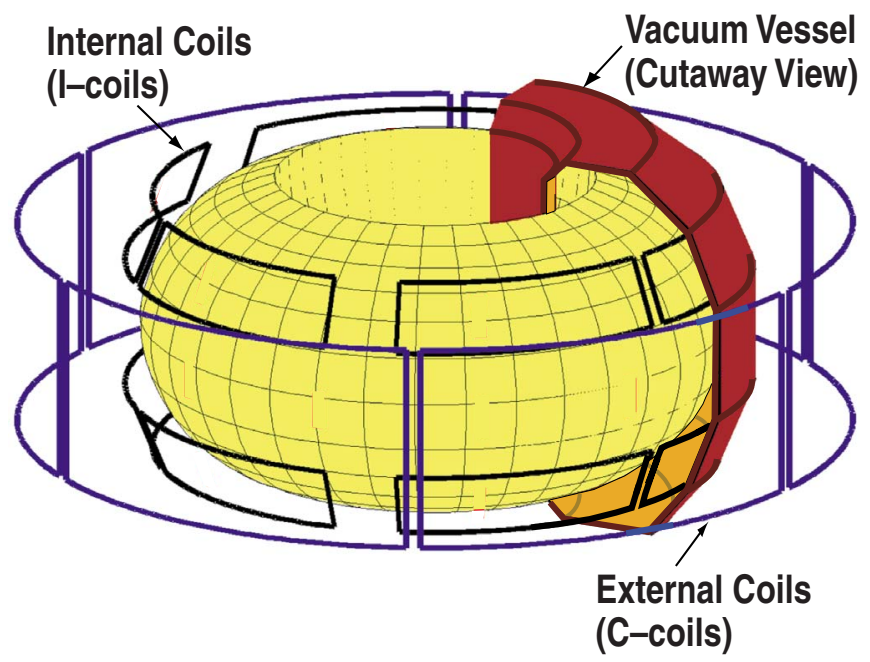

FIG. 1. (Color online) Plasma and coil geometry including (a) high triangularity ISS plasma showing the optimal position of the outer strike point for pumping, the location of the gas injection used in the pedestal density scan, the location of the $D_{\alpha}$ line integrated measurement used to estimate the ELM size, and the locations of the I- and C-coils, and (b) 3D rendering of the I-coil and C-coil geometry.

$n=3$ and the C-coils were configured for $n=1$ helicity. The I-coils can be configured for up/down even parity (upper and lower coil pairs having current in the same direction) or odd parity (currents in the opposite direction). 


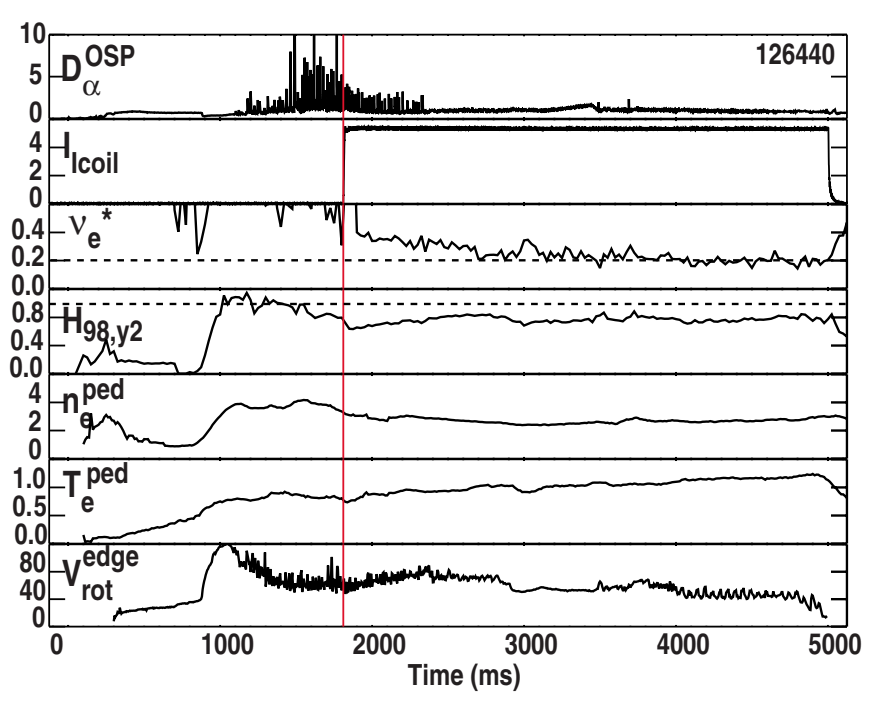

FIG. 2. (Color online) Time histories of plasma parameters for a typical ELM suppression discharge showing (a) outer divertor $D_{\alpha}$ intensity $\left(10^{17} \mathrm{phot} / \mathrm{m}^{2} / \mathrm{s} / \mathrm{str}\right)$, (b) I-coil current (kA), (c) pedestal electron collisionality, $\nu^{*}$, from Ref. 8, (d) confinement factor $\mathrm{H}(98, \mathrm{y} 2)$ from Ref. 4, (e) pedestal electron density $\left(10^{19} \mathrm{~m}^{-3}\right)$, (f) pedestal electron temperature $(\mathrm{keV})$, and $(\mathrm{g})$ toroidal rotation near the top of the pedestal $(\mathrm{km} / \mathrm{s})$.

The data will show that the effectiveness of the helical field perturbations for ELM suppression appears to be correlated with the radial extent of the region in which the magnetic islands produced by the field perturbations overlap. The calculation of the extent of the island overlap region is done with the SURFMN code. ${ }^{53}$ This vacuum-fields calculation does not include the plasma response such as rotational shielding effects or resonant field amplification. For $n=3$ even parity, Fig. 3 shows a typical poloidal mode spectrum calculated by SURFMN for a typical discharge used in these experiments.

The best ELM suppression is typically obtained when the peak in the mode spectrum is pitch aligned with the safety factor in the edge plasma, as in the example of Fig. 3 where $m=-n q(\Psi)$ is aligned with the local maximum in the

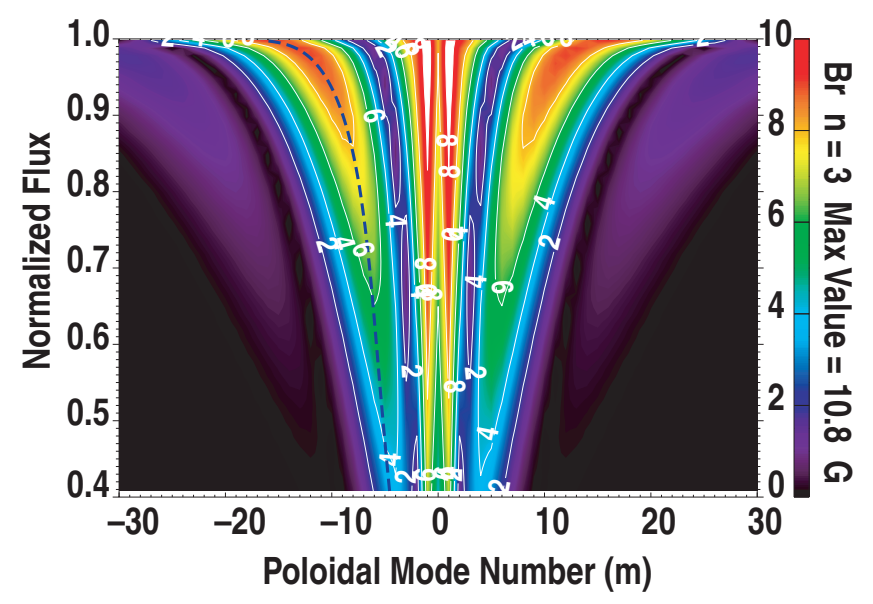

FIG. 3. (Color) Contours of poloidal mode spectrum of $n=3$ perturbation from the I-coils configured with even parity as a function of poloidal mode number and normalized poloidal flux in the plasma. For oppositely directed $B_{T}$ and $I_{p}$ in DIII-D, resonant modes from the I-coil have negative poloidal mode number. Pitch resonant modes with $m=-n q\left(\Psi_{N}\right)$ are shown by the blue dashed line.

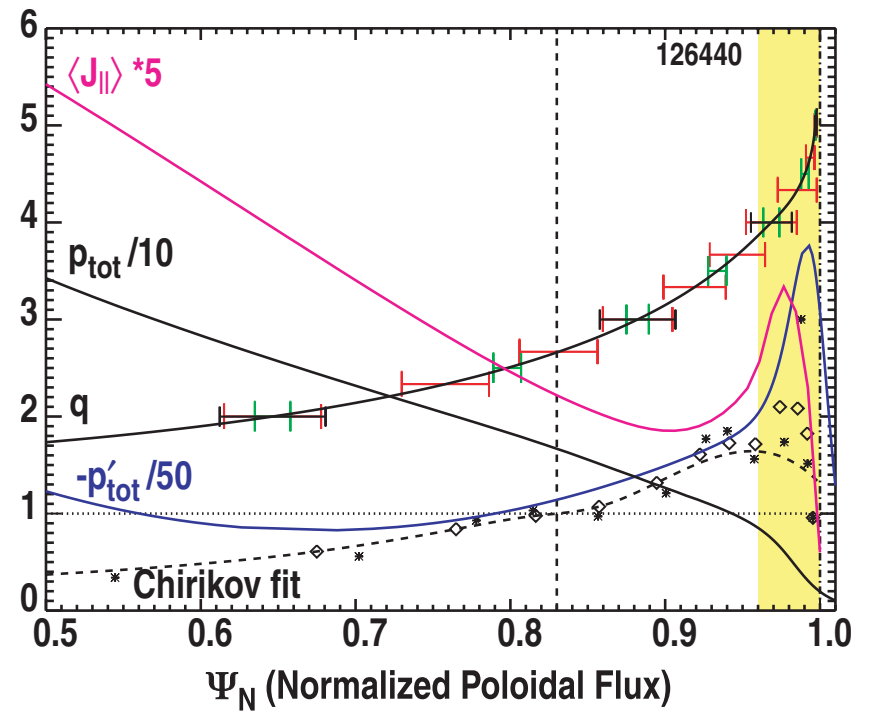

FIG. 4. (Color) Radial profiles of magnetic and plasma parameters at $2500 \mathrm{~ms}$ in the plasma of Fig. 2 including the structure of the magnetic islands from the I-coil ( $n=3$, red), C-coil $(n=1$, black) and intrinsic error fields $(n=2$, green and contributions to $n=1,3)$ aligned in pitch resonance with the experimental $q$-profile. Also shown are the profile of the calculated Chirikov parameter and the fit (dashed curve) used to determine the width of the region with the Chirikov parameter $>1.0$. Vertical dashed lines indicate separatrix of axisymmetric equilibrium $\left(\Psi_{N}=1\right)$ and location of the Chirikov parameter $=1.0$ from the fit $\left(\Psi_{N}=0.83\right)$. Scaled profiles of the total plasma pressure $(\mathrm{kPa})$, the gradient of total plasma pressure $\left(\mathrm{kPa} / \psi_{N}\right)$, and the corresponding edge parallel current including the bootstrap current contribution $\left(\mathrm{MA} / \mathrm{m}^{2}\right)$ are shown for comparison. The edge pressure pedestal is shown by the yellow shaded region.

mode spectrum from the $q=2$ surface out to the separatrix. Calculations of the location and widths of the resulting islands (Fig. 4) during the ELM suppressed phase of the discharge in Fig. 2 show that the islands are well overlapped in the plasma edge region. The overlap region is significantly wider than the edge pressure pedestal region.

The Chirikov parameter ${ }^{54}$ provides a useful measure to assess the degree of island overlap and field-line stochasticity for this discussion. For any adjacent pair of magnetic islands, it is defined as the average island width normalized to the inter-island radial spacing. Significant field stochasticity is indicated by the Chirikov parameter $>1.0$, although nonlinear effects cause a small level of stochasticity for values down to 0.7. In the discussion below, the width of the region where the Chirikov parameter is $>1.0$ is calculated by fitting the discrete set of Chirikov parameter values for each pair of adjacent islands in the edge to a smooth function of normalized magnetic flux. This width in $\Psi_{N}$, denoted by $\Delta_{\text {chir }>1}$, will be used as representative of the width of the island overlap region. In the example of Fig. 4 $\Delta_{\text {chir }>1} / \Delta_{\text {ptot }}^{\text {ped }}=2.9$ during the ELM suppressed phase of the discharge, where $\Delta_{\text {ptot }}^{\text {ped }}$ is the width in $\Psi_{N}$ of the total pressure pedestal.

The experiments reported here used five techniques to vary the overlap of the perturbed magnetic islands in the edge plasma, viz. by varying: 1) The I-coil current, i.e., the strength of the applied $n=3 \mathrm{RMP}, 2)$ the toroidal field at fixed $q_{95}$ (i.e. $I_{p} \sim B_{T}$ ) and RMP perturbation, 3) gas puffing to raise the edge plasma density, $n_{e}^{\text {ped }}$, thereby changing the 
TABLE I. Systems parameters for the five parametric scans considered in this paper.

\begin{tabular}{lccccccc}
\hline \hline Scan & Parity & $\begin{array}{c}\mathrm{I}_{\mathrm{I}-\text { coil }} \\
(\mathrm{kA})\end{array}$ & $\begin{array}{c}\text { C-coil } \\
\text { Multiplier }\end{array}$ & $\begin{array}{c}I_{p} \\
(\mathrm{MA})\end{array}$ & $\begin{array}{c}B_{T} \\
(\mathrm{~T})\end{array}$ & $\begin{array}{c}\text { Gas } \\
(\mathrm{Tl} / \mathrm{s})\end{array}$ \\
\hline $\begin{array}{l}\text { I-coil current } \\
\delta b r / B_{T}\end{array}$ & Even & $0-6.3$ & 1.0 & 1.68 & 2.14 & 3.60 & 0 \\
$n_{e}^{\text {ped }}$ & Even & 5.8 & 1.0 & $1.4-1.68$ & $1.77-2.14$ & 3.60 & 0 \\
High $q_{95}$ & Even & 4.0 & 1.0 & 1.55 & 1.93 & 3.53 & 0.85, \\
$n=3+n=1$ & Odd & $0,5.5,6.3$ & 1.0 & $0.81-0.93$ & 1.93 & $6.30,7.50$ & 0 \\
in $q$-scan & Even & $3.0,4.0$ & $1.0,1.2$, & $1.34-1.70$ & 1.93 & $3.25-4.18$ & 0 \\
\hline \hline
\end{tabular}

edge bootstrap current and magnetic shear, 4) the range of $q_{95}$ values in combination with the up-down parity of the applied $n=3$ RMP, and 5) the combination of $n=3$ and $n=1$ perturbations in $q_{95}$ scans through variation in $I_{p}$ at fixed $B_{T}$. In all cases, the basic C-coil current was set by a control algorithm that calculates the experimentally determined optimum $n=1$ error field correction current. ${ }^{55}$ The algorithm used a linear combination of two actuators, $I_{p}$ and the toroidal field coil current, to adjust the C-coil current and phase for empirical correction of field errors due to the toroidal and poloidal equilibrium coils. To vary the mixture of $n=3$ and $n=1$ fields, the leading coefficient in the algorithm (the C-coil multiplier) was increased to add additional $n=1$ field to the perturbation spectrum. This was done in an attempt to "fill-in" regions of the island profile and achieve island overlap deeper into the edge plasma. Parameters from the various scans are compiled in Table I.

\section{EXPERIMENTAL RESULTS}

Linear peeling-ballooning (P-B) stability analysis with the ELITE code ${ }^{56-58}$ indicates that in the ISS plasmas, suppression of Type-I ELMs occurs because application of $n=3$ RMPs moves the pedestal plasma operating point from the unstable region to the stable region, ${ }^{10,59}$ as was observed in lower triangularity plasmas with the ITER pedestal collisionality. The linear P-B calculations indicate that the ELM stabilization by the RMPs is due to reductions of both the pedestal pressure gradient and the calculated edge bootstrap current. This comes primarily from a reduction of the density and density gradient in the pedestal. Although the location of the stable region in the P-B space, parameterized by the pressure gradient and edge current, is somewhat different for the ISS plasmas versus lower triangularity discharges (as discussed in Ref. 59) the interpretation of the stabilization mechanism is consistent in the different shapes.

With fixed plasma shape and safety factor $q \sim B_{T} / I_{p}$, discharges with RMP show an initial rapid change of the pedestal density and ELM character at I-coil turn-on, with full ELM suppression occurring later in the discharges. This behavior holds for scans over a range in (1) the $n=3$ RMP from the I-coil, (2) the $n=3$ perturbation normalized to the toroidal field, $\delta b r / B_{T}$, at fixed I-coil current, and (3) pedestal plasma parameters using gas puffing at fixed I-coil current. Here $\delta b r$ is the radial perturbation field.
Time histories from the I-coil current scan (Fig. 5) at fixed $B_{T}$ and $I_{p}$ show that when the I-coil is first turned on, there is a reduction of the pedestal density and a change in the ELM character (amplitude and frequency), but full suppression does not occur immediately. ELM suppression does occur progressively earlier in the discharge as I-coil current increases. After the initial rapid decrease at the I-coil turn-on, the pedestal density decreases very slowly during the ELM suppression phase. The scans of $\delta b r / B_{\mathrm{T}}$ at constant I-coil current and constant edge safety factor $q_{95}$ were done by lowering the toroidal field and plasma current together on a shot-to-shot basis. Time histories (Fig. 6) again show an immediate change in ELM character at I-coil turn-on with full suppression occurring later in the discharge. Finally, the scans of pedestal plasma parameters at fixed I-coil current

10

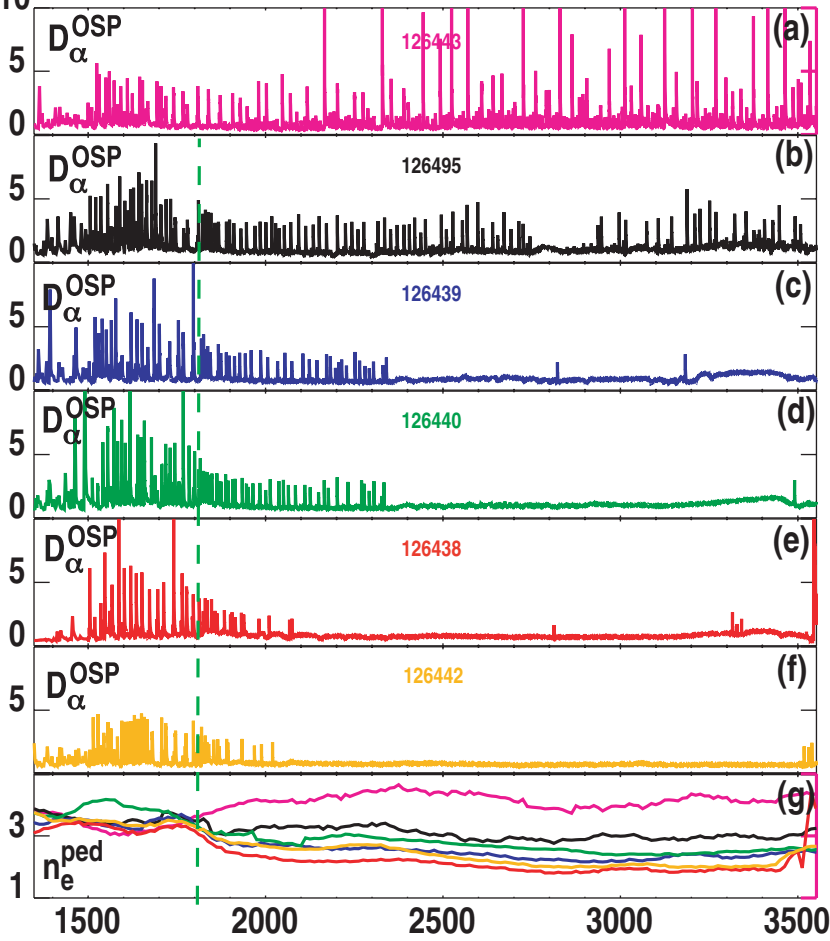

FIG. 5. (Color) Time histories of multiple discharges in the scan of I-coil current, showing [(a)-(f) $] D_{\alpha}$ intensity $\left(10^{17} \mathrm{photons} / \mathrm{m}^{2} / \mathrm{s} / \mathrm{str}\right)$ for each discharge, and $(\mathrm{g})$ pedestal electron density $\left(10^{19} \mathrm{~m}^{-3}\right)$. I-coil current and $\delta b_{r}^{11 / 3} / B_{T}$ are (a) $0 \mathrm{kAt}, 0$, (b) $4.0 \mathrm{kAt}, 3.0 \times 10^{-4}$, (c) $4.8 \mathrm{kAt}, 3.7 \times 10^{-4}$, (d) $5.3 \mathrm{kAt}, 4.0 \times 10^{-4}$, (e) $5.7 \mathrm{kAt}, 4.4 \times 10^{-4}$, and (f) $6.3 \mathrm{kAt}, 4.9 \times 10^{-4}$. I-coil turn-on indicated by green dashed line. 


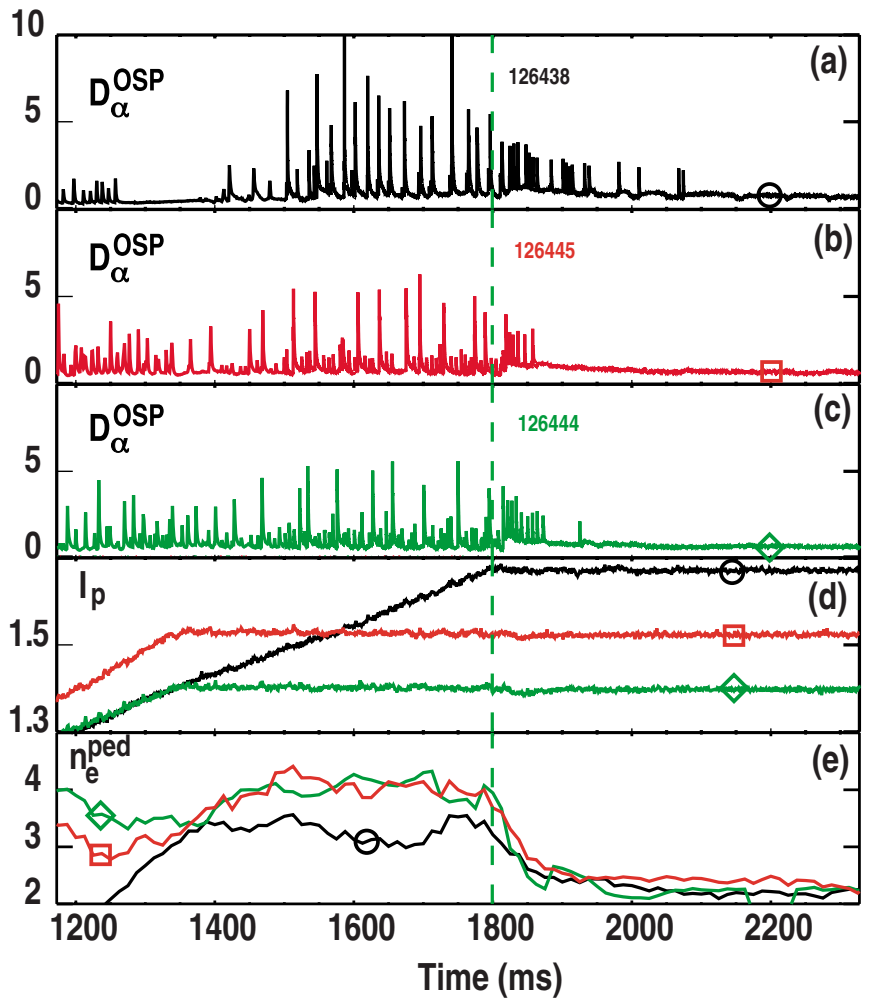

FIG. 6. (Color online) Time histories of multiple discharges in the scan of $\delta b_{r} / B_{T}$ at constant $B_{r} / I_{p}$, showing [(a)-(c)] $D_{\alpha}$ intensity $\left(10^{17}\right.$ photons $/ \mathrm{m}^{2} / \mathrm{s} / \mathrm{str}$ ) for each discharge, (d) $I_{p}$ (MA), and (e) pedestal electron density $\left(10^{19} \mathrm{~m}^{-3}\right)$. I-coil current $=5.7 \mathrm{kAt} . B_{T}$ and $\delta b_{r}^{11 / 3} / B_{T}$ are (a) $2.14 \mathrm{~T}$ and $4.4 \times 10^{-4}$, (b) $1.95 \mathrm{~T}$ and $4.7 \times 10^{-4}$, and (c) $1.75 \mathrm{~T}$ and $5.3 \times 10^{-4}$. I-coil turn-on indicated by green (dashed) line.

were done by adding a supplemental gas puff from the lower outer scrape-off layer (SOL) region [Fig. 1(a)]. Time histories (Fig. 7) show that this achieved a modest variation in pedestal electron density, temperature and pressure. Data from this scan provided the only variation of the island overlap in the database caused by changes in the edge $q$-profile without any change to the applied magnetic fields (equilibrium or RMP). For this scan, the variation of the gradient of total pedestal pressure $(20 \%-25 \%)$ and other factors in the calculation of the edge bootstrap current produced the change of $30 \%-35 \%$ in the peak bootstrap current that affected the edge $q$-profile.

A database of the ELM events from the I-coil current, $\delta b r / B_{T}$, and $n_{e}^{\text {ped }}$ scans described above was constructed to examine whether the width of the edge region with Chirikov parameter greater than 1.0 was a good ordering parameter of the maximum ELM size. This is one of many possible ordering parameters for maximum ELM size. To populate the database, multiple time slices at $50 \mathrm{~ms}$ intervals were selected from each discharge both before and during the I-coil-on phase. For each time slice a comprehensive analysis of the pedestal density and temperature profiles ${ }^{59,60}$ was done, including the effects of the pedestal impurity profile and fast ion pressure contributions from the beams. The profile analysis for time slices during an ELMing phase used edge Thomson scattering $\left(n_{e}\right.$ and $\left.T_{e}\right)$ and charge exchange recombination (CER) spectroscopy $\left(T_{i}\right.$, impurity density) data from the

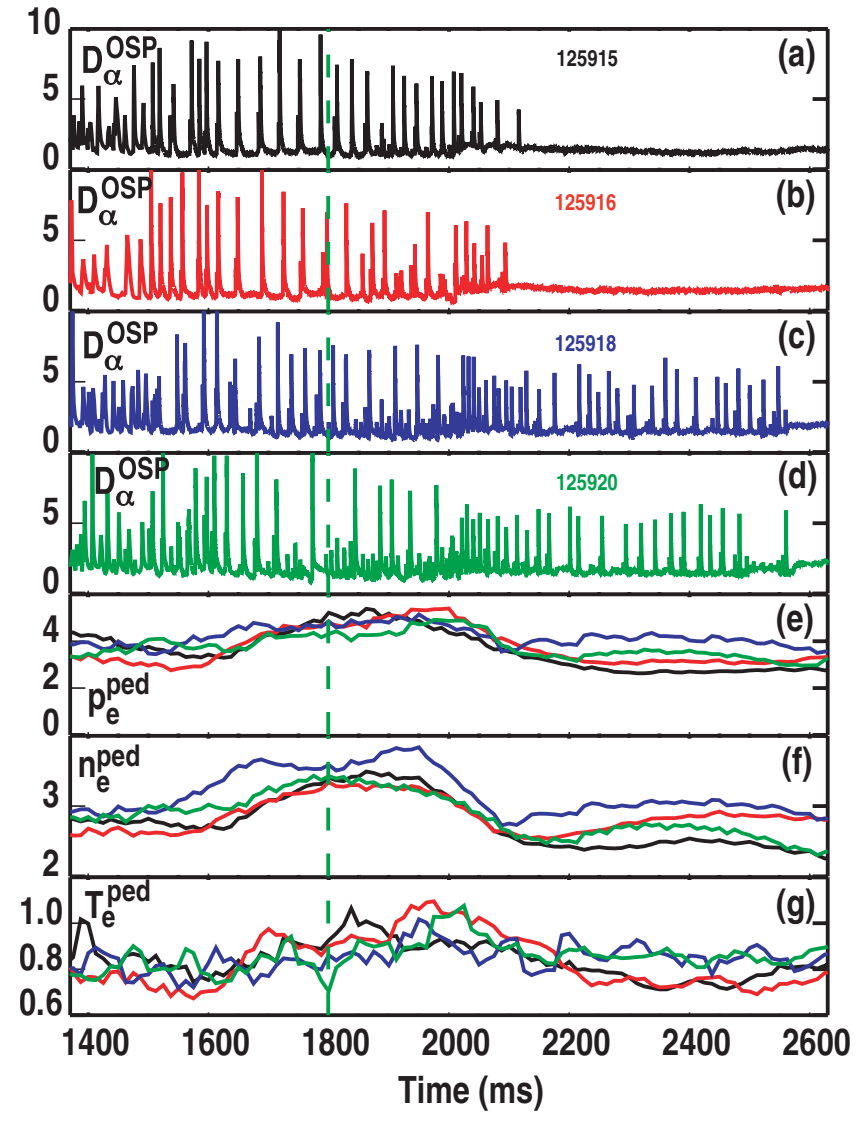

FIG. 7. (Color) Time histories of multiple discharges in the scan of pedestal pressure by gas puffing, showing $[(\mathrm{a})-(\mathrm{d})] D_{\alpha}$ intensity $\left(10^{17}\right.$ photons $/ \mathrm{m}^{2} / \mathrm{s} / \mathrm{str}$ ) for each discharge, (e) pedestal electron pressure, (f) pedestal electron density $\left(10^{19} \mathrm{~m}^{-3}\right)$, and $(\mathrm{g})$ pedestal electron temperature $(\mathrm{keV})$. Time average gas injection rates were (a) $0.85 \mathrm{TL} / \mathrm{s}$, (b), (c), (d) $2.2 \mathrm{Tl} / \mathrm{s}$. I-coil turn-on indicated by green dashed line.

period at the end (80\%-99\%) of the ELM cycles. For each time slice during the ELMing phase, the profiles were obtained by fitting all the data collected from the end of the ELM cycles for all ELMs in a window (typically $300 \mathrm{~ms}$ ) centered on the timeslice. Profiles during the ELM suppressed phases were formed from all the data within a $200 \mathrm{~ms}$ window centered on the timeslice. The axisymmetric equilibrium separatrix was placed at one fourth of the pedestal width outside the point of maximum gradient in the electron temperature profile to align the various data profiles with respect to the axisymmetric equilibrium separatrix at the outer midplane. ${ }^{61}$ Hyperbolic tangent fits to the pedestal density and temperature profiles were then used in the edge pedestal stability calculations.

In addition to the steps described above, several other calculations were required to generate data for the database. The axisymmetric equilibrium reconstruction, a so-called "kinetic EFIT" analysis, ${ }^{62}$ was completed for each timeslice to calculate the $q$ profile consistent with the measured pressure profile and the effects of the edge bootstrap current. This was important to do because the island overlap width is sensitive to the $q$-shear in the plasma edge. The current density in the $\mathrm{H}$-mode pedestal region was not measured in these experiments. Instead, the flux surface averaged current density used in the equilibrium calculations was set to the sum 
of the neoclassical bootstrap current, given by the Sauter expression, ${ }^{8}$ and the fully relaxed Ohmic current using neoclassical resistivity. Finally, a complete RMP mode spectrum analysis using the SURFMN code, ${ }^{53}$ including calculation of the Chirikov parameter profile in the edge, was done on each kinetic EFIT including the I-coil $n=3$ perturbation, the $n=1$ perturbation from the C-coil, and the measured $n=1,2$, and 3 error fields. ${ }^{63}$ This calculation used only the vacuum fields without any correction for the plasma response, so any effects of screening or amplification of the perturbation fields due to the plasma response are not included here. The profile of the Chirikov parameter values was fit with a spline to evaluate the width of the region with Chirikov parameter greater than 1.0.

The database shows that the maximum ELM size is well ordered by this width parameter and that a correlation exists between a threshold minimum width of the island overlap region and achieving complete ELM suppression. The scatter plot of ELM amplitude (from a $D_{\alpha}$ chord viewing the outer divertor leg) as a function of the width in normalized poloidal flux of the edge region with the Chirikov parameter $>1$ is shown in Fig. 8. All ELMs within a given kinetic EFIT $50 \mathrm{~ms}$ time window are plotted with the island overlap width for that window. Although a distribution of ELM amplitudes is observed at all values of the overlap region width, as would be expected given the normal variability of the nonlinear ELM instability, the data shows that the maximum ELM size is well ordered by this width parameter. Data for widths less than 0.07 [Fig. 8(a)] are from the phase before I-coil turn-on in which islands in the edge are due only to the applied $n=1$ error correction fields from the C-coil and the intrinsic error fields. An expansion of the plot for the range $0.1<\Delta_{\text {chir }>1}<0.25$ is given in Fig. 8(b). The data with widths $0.1<\Delta_{\text {chir }>1}<0.165$ are from phases with the I-coil on, including the transient phase immediately after I-coil turn-on, in which ELMs remain. When the vacuum island overlap width $\Delta_{\text {chir }>1}$ exceeds 0.165 , large Type-I ELMs are suppressed. This is shown by the reduction in the maximum $D_{\alpha}$ intensity by at least a factor of 10 . The data during the ELMing phase with the I-coil on also suggest that the maximum ELM $D_{\alpha}$ amplitude decreases with increasing width of the vacuum overlap region.

Scans of the edge safety factor $\left(q_{95}=\right.$ safety factor at 95\% poloidal flux) by variation of the plasma current, show that complete suppression of ELMs by application of RMPs is a resonant phenomenon that depends sensitively on the $q$-profile. All of the experiments to date have used upward $I_{p}$ ramps $\left(d I_{p} / d t=0.18 \mathrm{MA} / \mathrm{s}\right)$ at fixed $B_{T}$ to produce downward ramps of the edge safety factor $q_{95}$. The possible effect of the current ramp on the edge current density was not taken into account at this stage. As an example, the discharge in Fig. 9 has $3.0 \mathrm{kA}$ in the I-coil and the nominal error field correction current in the $\mathrm{C}$-coil. It shows a window in $q_{95}$ for ELM suppression during the $I_{p}$ ramp with extended periods of ELM suppression observed for $3.32<q_{95}<3.67$, i.e., $\Delta q_{95}=0.35$.

The statement that ELM suppression using RMPs is a resonance phenomenon is further supported by observations of extremely large reduction in Type-I ELM size and in-
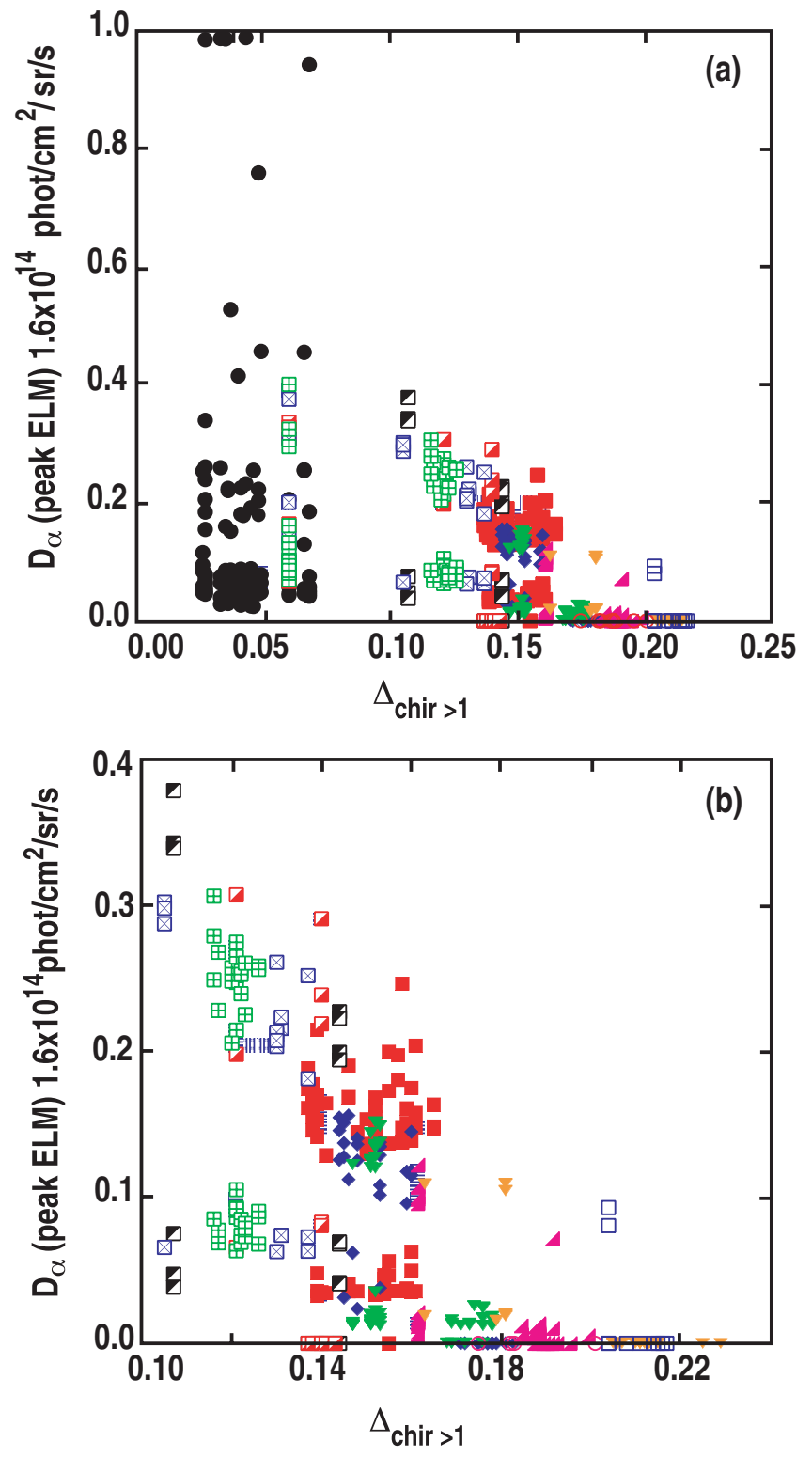

FIG. 8. (Color online) Peak magnitude of ELM transient on outer strike point $D_{\alpha}$ signal as a function of the width in normalized flux of the vacuum island overlap region with the Chirikov parameter $>1.0\left(\Delta_{\text {chir }>1}\right)$ for multiple transients in the discharges from Figs. 6-8. (a) The value of ELM size plotted is normalized to the maximum size of the ELMs in the H-mode phase prior to application of the I-coil RMP field. (b) Plot expanded for timeslices with the RMP coil on.

crease in ELM frequency in low collisionality plasmas at $q_{95} \sim 7.5$ using pitch resonant $n=3$ RMPs with the odd parity connection of the upper and lower rows of the I-coils. The poloidal mode spectrum plot (Fig. 10) for this case shows good alignment of pitch resonant modes $[m=-n q(\Psi)]$ with a local peak in the spectrum in the edge plasma. These plasmas extend the results of previous experiments ${ }^{10,15-19}$ in high collisionality plasmas using odd parity $n=3$ RMPs from the I-coil, to the low ITER-like collisionality regime. The previous $\nu_{e}^{*} \sim 1.0$ discharges using odd parity $n=3$ RMPs were run at $q_{95}=3.7$ and therefore had very little resonant field component in the perturbation spectrum. In those discharges the perturbation spectrum was dominated by nonresonant field components and Type-I ELMs were replaced by very 


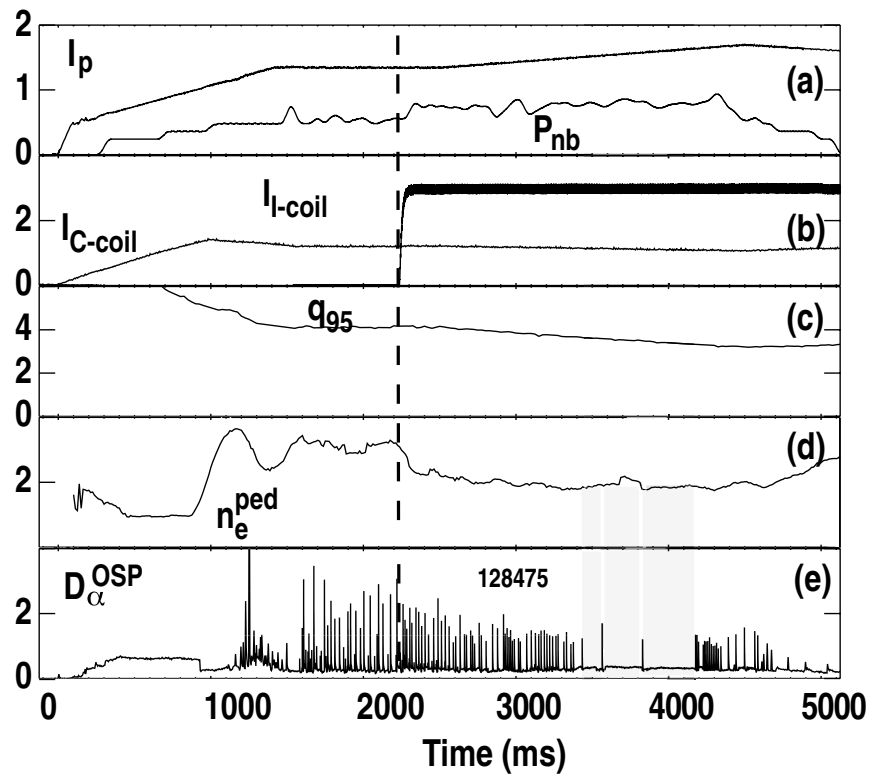

FIG. 9. Time histories of parameters from a typical discharge with an $I_{p}$ up ramp ( $q_{95}$ down ramp) used to identify the $q$-window for ELM suppression with $n=3$ RMPs from the I-coil, including (a) $I_{p}$ (MA) and injected neutral beam power $P_{\mathrm{nb}}(\mathrm{MW}) / 10$, (b) I-coil and C-coil currents (kA), (c) $q_{95}$ from standard EFITs, (d) pedestal electron density $\left(10^{19} \mathrm{~m}^{-3}\right)$, and (e) outer divertor $D_{\alpha}$ intensity $\left(10^{17}\right.$ photons $\left./ \mathrm{m}^{2} / \mathrm{s} / \mathrm{str}\right)$. Shaded regions indicate periods of ELM suppression.

small, very high frequency Type-II ELMs without substantial change in the pedestal parameters. ${ }^{10}$ At low collisionality in the recent experiments (Fig. 11), the Type-I ELM size was substantially reduced (factor of 18) and the frequency substantially increased (factor of 4). ${ }^{59}$ Initial analysis of the plasma profiles showed that the pressure and pressure gradient were reduced, primarily due to reductions in the density, as in the low $q_{95}$ even parity I-coil plasmas at low collisionality. However, the ELMs that remained at high $q_{95}$ with odd parity RMP had lower normalized energy loss

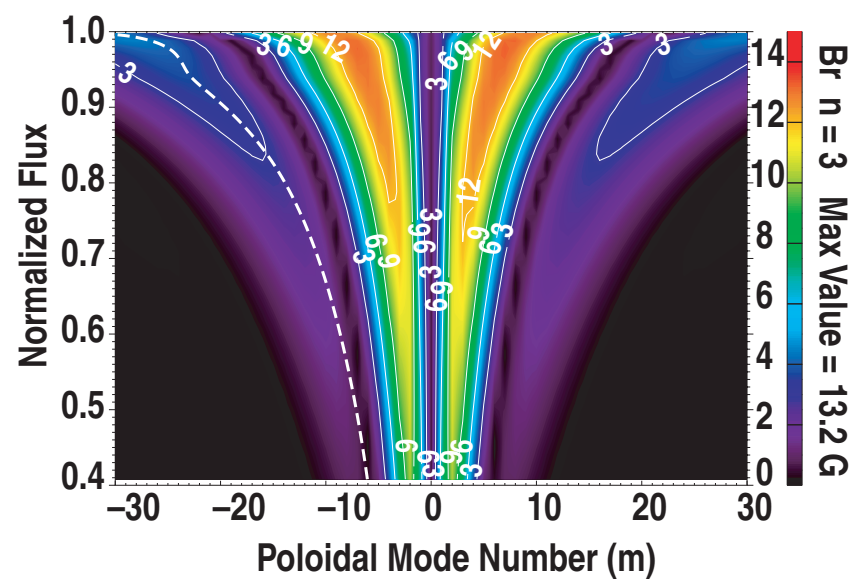

FIG. 10. (Color) Contours of poloidal mode spectrum of $n=3$ perturbation from the I-coils configured with odd parity as a function of poloidal mode number and normalized poloidal flux in the plasma. For oppositely directed $B_{T}$ and $I_{p}$ in DIII-D, resonant modes from the I-coil have negative poloidal mode number. Pitch resonant modes with $m=-n q\left(\Psi_{N}\right)$ are shown by the white dashed line.

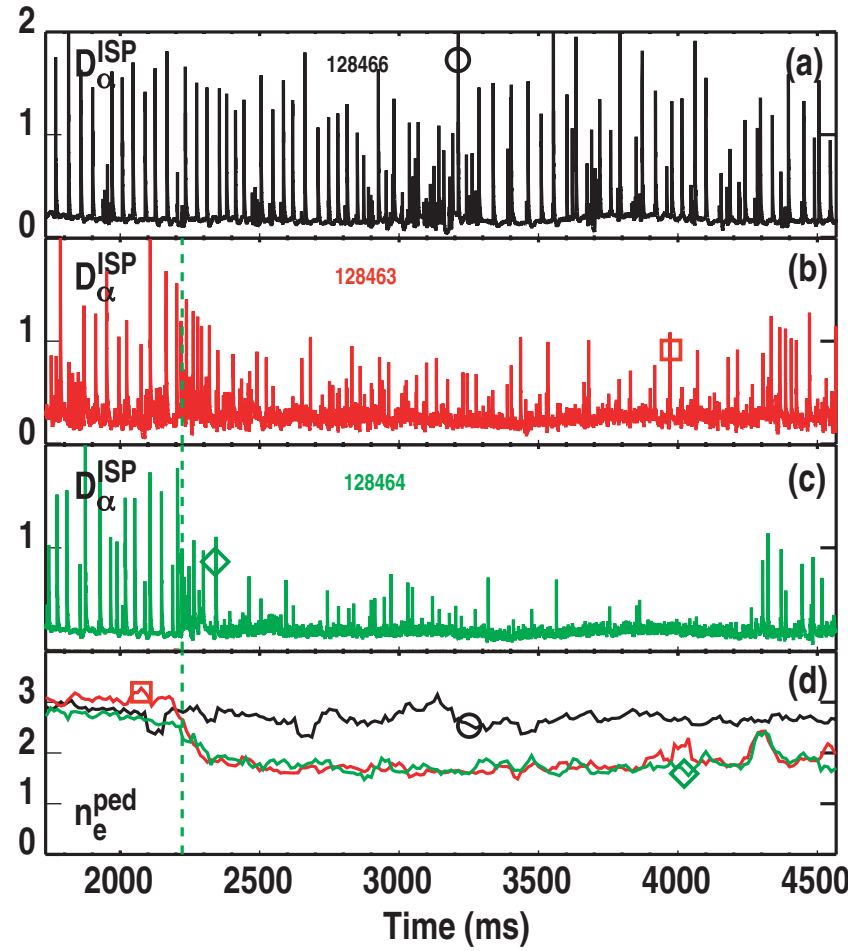

FIG. 11. (Color online) Time histories of parameters from discharges at high $q_{95}=7.5$ with odd parity, $n=3$ RMPs from the I-coil, including [(a)-(c)] ISP $D_{\alpha}$ intensity $\left(10^{18}\right.$ photons $\left./ \mathrm{m}^{2} / \mathrm{s} / \mathrm{str}\right)$ for each discharge and (d) pedestal electron density $\left(10^{19} \mathrm{~m}^{-3}\right)$. I-coil current, $q_{95}$ and $\delta b_{r}^{23 / 3} / B_{T}$ are (a) $0 \mathrm{kAt}$, $7.5,0$, (b) $5.7 \mathrm{kAt}, 6.2,0.70 \times 10^{-4}$, and (c) $6.3 \mathrm{kAt}, 7.5,0.78 \times 10^{-4}$. I-coil turn-on time indicated by green (dashed) line.

$\left(\Delta W_{\mathrm{ELM}} / W_{\mathrm{PED}}\right)$ than the ELMs before the coil turn-on ${ }^{59}$ in addition to the large reduction in absolute energy loss.

The range of $q$-profiles for which complete ELM suppression is obtained can be expanded by increasing the $n=3$ perturbation strength or by increasing the contributions of $n=1$ perturbations to "fill-in" the overlap of the edge islands (Fig. 12). On a shot-by-shot basis either the current in the I-coil or the current in the $\mathrm{C}$-coil was increased to increase the $n=3$ or $n=1$ perturbation fields, respectively. As $I_{p}$ was ramped up slowly a resonance window was found in which ELMs were suppressed. The range of $q_{95}$ over which ELMs were suppressed increased when either the current in the C-coil was increased [Figs. 12(b) and 12(c)] or when the I-coil current was increased [Figs. 12(a) and 12(b)]. Detailed analysis of the pedestal profiles from these discharges showed that for comparable $q$-profiles, suppressing ELMs by adding additional $n=1$ perturbation reduced the pedestal pressure and peak pressure gradient more than achieving suppression by increasing the strength of the $n=3$ perturbation. So these discharges provide the existence proof that the resonance window for suppression can be increased by using combinations of perturbation spectra with different toroidal mode number, but they also show that the degradation of the pedestal performance may be greater when low- $n$ perturbations are used.

The response of the pedestal density to the RMP suggests that the underlying physics determining the pedestal 


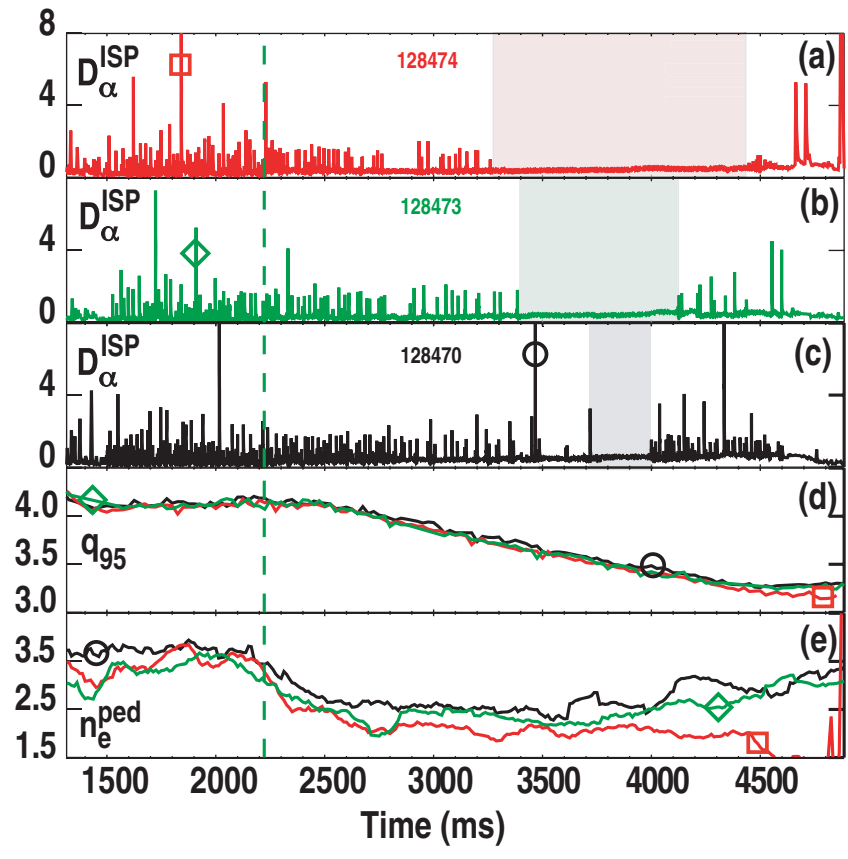

FIG. 12. (Color online) Time histories of parameters from discharges with different combinations of $n=3$ RMP from the I-coil and $n=1$ perturbation from the C-coil, including $[(\mathrm{a})-(\mathrm{c})]$ ISP $D_{\alpha}$ intensity $\left(10^{18}\right.$ photons $/ \mathrm{m}^{2} / \mathrm{s} / \mathrm{str}$ ) for each discharge, (d) $q_{95}$ from standard EFITs, and (e) pedestal electron density $\left(10^{19} \mathrm{~m}^{-3}\right)$. I-coil current, $\delta b_{r}^{11 / 3} / B_{T}$, and C-coil current are (a)=4.0 kAt, $3.2 \times 10^{-4}, 9.6 \mathrm{kAt}$, (b) $3.0 \mathrm{kAt}, 2.5 \times 10^{-4}$, $9.6 \mathrm{kAt}$, and (c) $3.0 \mathrm{kAt}, 2.5 \times 10^{-4}, 4.8 \mathrm{kAt}$. I-coil turn-on time indicated by green (dashed) line.

particle balance during the RMP (transport and sources) may be different than the physics setting the resonance window for suppression of the ELM instability. The density reduction that is typically seen when the RMP fields are turned on in low collisionality plasmas is not as sensitive to the safety factor as is the complete suppression of the Type-I ELMs. The reduction of the line averaged density and of the pedestal density [Figs. 5(g), 6(e), 7(f), and 12(e)] is similar in discharges for which the I-coil (and C-coil) perturbations are turned on at high $q_{95}$ prior to a $q_{95}$ down ramp [Fig. 12(e)] and for plasmas with lower $q_{95}$ at the turn-on time [Figs. $5(\mathrm{~g}), 6(\mathrm{e})$, and $7(\mathrm{f})]$. In addition, the pedestal density can be essentially insensitive to the value of $q_{95}$ during the $I_{p}$ ramps despite the sharp sensitivity of complete suppression of the ELMs to the safety factor. However, the edge stability depends on the details of the edge pressure (density and temperature) profiles and the edge current profile which are evolving during the $q_{95}$ ramps. Detailed time dependent stability calculations for the $q_{95}$ ramp discharges must also take into account currents induced in the edge by the $I_{p}$ ramps. These must be evaluated with a time-dependent current diffusion calculation. Finally, these observations also suggest that there may be factors due to the RMP such as direct effects on the edge current etc., in addition to the change in the pressure profile due to the changes in density profiles, determining the sharp resonance window in the $q$-profile for satisfying P-B stability and achieving complete ELM suppression.

\section{DISCUSSION OF THEORY: EXPERIMENT COMPARISON}

The correlation of ELM suppression with a minimum width of the vacuum island overlap region provides a clue to the physics driving the suppression. Another clue is that frequently the largest change in the pressure gradient, between plasmas at low RMP strength that still have ELMs and ELM suppressed plasmas with stronger RMP, occurs in approximately the same edge plasma location as the inner edge of the island overlap region. This threshold region, $0.85<\Psi_{N}<0.9$, is significantly inboard of the steep gradient region in the pedestal. Peeling-ballooning (P-B) stability analysis has shown that when ELMs are suppressed by RMPs the operating point in edge pressure gradient versus edge current density $(\alpha-J)$ space is within the stable region. Therefore the key to understanding why increased island overlap is correlated with suppression is to understand how overlapping islands in the threshold region help to move the edge pressure and the corresponding edge bootstrap current from the unstable region (consistent with ELMing) toward the P-B stability boundary. One step toward this understanding is to look for differences in the number of magnetic field lines that are lost from the confined plasma, i.e., connected from the threshold region to material surfaces, between cases at low RMP strength that are ELMing and ELM suppressed cases at higher RMP strength.

There is a clear increase in the number of field lines lost from the confined plasma in cases with ELM suppression compared with similar plasmas at lower RMP strength that do not achieve suppression. Detailed field line tracing calculations were done with the TRIP3D code. ${ }^{64,65}$ A total of 1800 field lines were traced in 10 groups of 180 lines each. The launch locations of the lines in each group were uniformly distributed spatially on a poloidal flux surface from the axisymmetric kinetic equilibrium reconstruction. The 10 groups covered the flux surfaces from $0.75 \leq \Psi_{N} \leq 0.95$ in steps of $\Delta \Psi_{N}=0.02$. The field lines were traced in the forward direction, toward the outer divertor target, until they either hit the target or they completed 200 toroidal revolutions. The full $3 \mathrm{D}$ geometry of all the vacuum magnetic fields in the experiment, including those due to the I-coil, the C-coil, and the intrinsic error fields was included.

A comparison of the field line loss fraction (i.e., the fraction that hit the target in less than 200 revolutions) as a function of the flux surface where the field lines were initially launched shows increased field line loss over a substantial region of the plasma edge in ELM suppressed cases. For three of the cases from the I-coil current scan (Fig. 5), this analysis (Fig. 13) shows increases of between $30 \%$ and $40 \%$ in the fractional field line loss over the region $0.83<\Psi_{N}<0.89$ for the two ELM suppressed cases at higher I-coil current (RMP strength) compared with the ELMing case at lower I-coil current. Smaller increases in the fractional field line loss are observed even further into the plasma, although the statistical significance of the difference is marginal due to low sampling rates. The vacuum fields analysis indicates that the region $0.89<\Psi_{N}<0.95$ is highly stochastic in both the ELMing and ELM suppressed dis- 


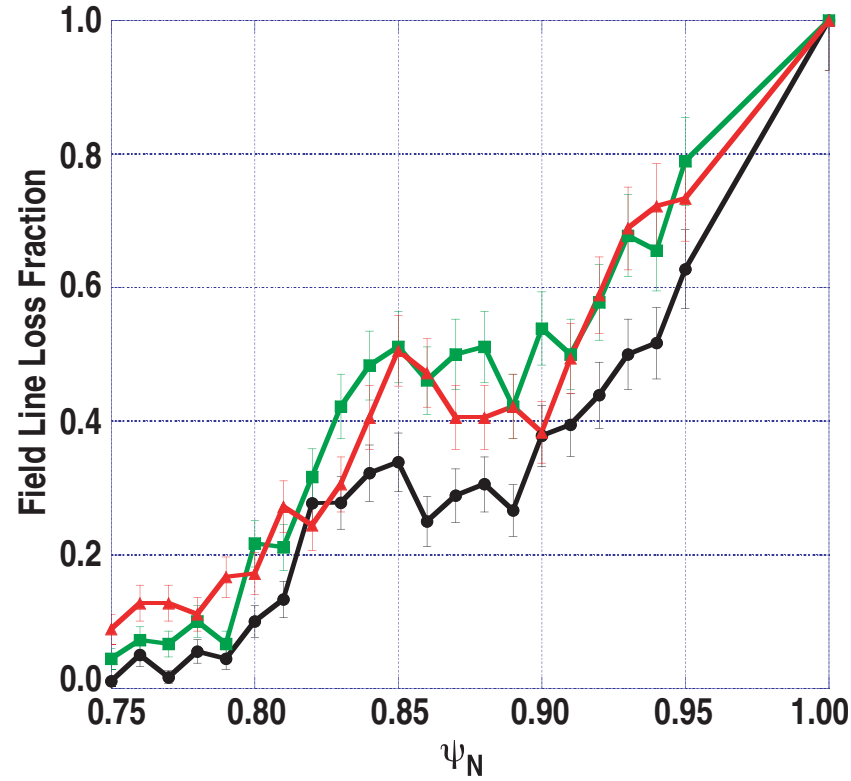

FIG. 13. (Color) Results from the field line tracing calculations as functions of normalized poloidal flux for the $4.0 \mathrm{kAt}$ (black), $5.3 \mathrm{kAt}$ (green), and $5.7 \mathrm{kAt}$ (red) cases in the I-coil current scan $\left[D_{\alpha}\right.$ traces in Figs. 5(b), 5(d), and $5(\mathrm{e})]$, showing fraction of field lines that strike the outer divertor target.

charges, so the direct connection of the increased field line loss in this region with completely suppressing ELMs is not immediately clear. However, there is a qualitative difference in the degree of stochasticity in the region $0.83<\Psi_{N}<0.89$ between the cases with full ELM suppression and the case that has ELMs at lower I-coil current. This suggests that the increased field line loss in this region may play an important role in achieving complete suppression of ELMs.

The fraction of the field lines that were lost with forward connection length to the outer divertor target less than two electron-ion collisional mean-free-paths (mfps) (Fig. 14) also shows an increase across the region of $0.83<\Psi_{N}<0.89$. Here the local collisional $\mathrm{mfp}$ $\lambda_{\mathrm{mfp}}=45.7\left(T_{e}^{\mathrm{ped}}\right)^{2} /\left(Z_{\mathrm{eff}} \mathrm{f}_{e}^{\mathrm{ped}} \log \Lambda\right)$ at the origin of the field line in the pedestal is used for the normalization, where $T_{e}^{\text {ped }}$ and $n_{e}^{\text {ped }}$ are the pedestal electron temperature and density, respectively, and $\log \Lambda=15.2-0.5 \log \left(n_{e}\right)+\log \left(T_{e}\right)$ with $T_{e}^{\text {ped }}$ in $\mathrm{keV}$ and $n_{e}^{\text {ped }}$ in $10^{20} \mathrm{~m}^{-3}$. The largest relative increase in the fractional loss of these short field lines is in the region $0.86<\Psi_{N}<0.89$. The change in the fractional loss of field lines with connection length less than 3 or 5 collisional mfps is even more pronounced in the region $0.85<\Psi_{N}<0.90$ (not shown).

These results suggest that changes in the plasma potential in the region $0.83<\Psi_{N}<0.9$ could play an important role in the physics processes that move the pedestal operating point inside the stable region of the P-B stability boundary in the ELM suppressed cases. The plasma in this region that is connected to the divertor targets on the short field lines will be at a very different potential than the well confined plasma on nearby field lines that have long (or infinite) connection length. It has been suggested ${ }^{12,41-43,66}$ that the electric fields generated by such variations in plasma poten-

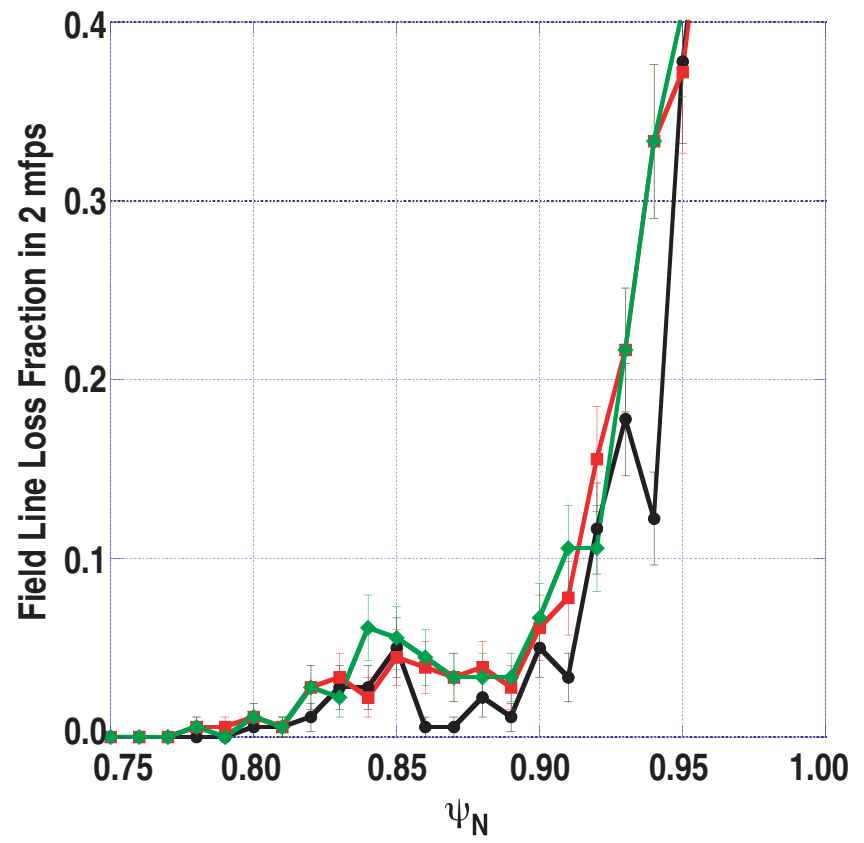

FIG. 14. (Color) Fraction of field lines lost to the outer divertor target with connection length less than two electron-ion mean free path lengths for the three discharges of Fig. 13.

tial could produce $E \times B$ convection cells that might increase the particle transport within the edge plasma. This is at least qualitatively consistent with the observations of reduced plasma pressure gradients, due primarily to reduced density gradients, seen in this region in the ELM suppressed cases. However, work remains to be done to verify that this model is consistent with the observations of pedestal density reductions when the RMP is turned on in plasmas with the $q$-profile outside the resonance window for ELM suppression. Connecting both the insensitivity of the initial pedestal density reduction to the $q$-profile at RMP turn-on and the subsequent insensitivity of the pedestal density to variations in the $q$-profile during safety factor ramps, with a model asserting that $E \times B$ convective cells contribute to increased particle transport from inside the top of the pedestal remains a topic for future analysis.

Finally, although work continues on the basic physics driving the suppression of ELMs by RMPs, the simple picture described here can provide guidance to initial studies of candidate coil designs for future tokamaks such as ITER. Recent work surveyed a range of possible RMP coil designs for ELM control in ITER.$^{53}$ In this kind of survey the first specification that must be made is the current required in the coils to satisfy a criterion for ELM suppression. From the results reported here, an initial estimate of the required coil currents for the different candidate designs was made based on a criterion that the coils must produce a Chirikov parameter greater than 1.0 from the plasma edge to $\Psi_{N}=0.85$. The calculations for ITER were done with vacuum perturbation fields consistent with the data analysis above. Although there is significant uncertainty in the predictions of the ITER pedestal width, and therefore the expected bootstrap current and $q$-profile in the ITER pedestal region, the effect of this uncertainty on the required coil currents was not studied. This 
initial work allowed estimates of the mode spectra of the different designs to be examined and initial estimates of the space necessary for the conductors to carry the estimated currents to be made and discussed. ${ }^{53,67}$ Work to refine these estimates will certainly continue in this area.

\section{CONCLUSIONS}

ELM suppression was achieved in plasmas with an ISS and pedestal electron collisionality similar to that expected for ITER, $\nu_{e}^{*}=0.1$, for a wide range of $n=3$ RMP field strength, for a range of combinations of $n=3$ and $n=1$ perturbation fields, and for a range of safety factor profiles. The data indicates that full suppression of Type-I ELMs is a resonant phenomenon that depends sensitively on the safety factor profile. The range of $q$-profiles that achieved full suppression was increased either by increasing the strength of the $n=3$ RMP fields, or by increasing the strength of $n=1$ fields only in combination with sufficiently strong $n=3$ fields.

A simple model that proposes that the maximum ELM size observed would be related to the width of the region in the edge plasma with good overlap of the vacuum magnetic islands, is qualitatively consistent with the data from I-coil current, $B_{T}$, and gas puffing scans in plasmas with the ISS and fixed $q_{95}$ in the resonance window for full ELM suppression. Reduction of the ELM size, measured by $D_{\alpha}$ signals in the divertor, to less than 5\% of the ELM size without RMPs is correlated with vacuum island overlap width in the edge greater than a threshold value. Initial field line tracing calculations using the vacuum fields showed an increase in the number of field lines lost, with short connection length to the divertor targets, from the same region as the increase in island overlap in an ELM suppressed case compared with an ELMing case. This may suggest a role for $E \times B$ convection in changing the pedestal profiles in such a way as to satisfy P-B stability and suppress ELMs.

The ordering of maximum ELM size with island overlap region width holds for datasets from plasmas with fixed shape and $q_{95}$ in which the applied RMP fields from the coils or the pedestal density are varied, but not in comparisons between plasmas with significantly different $q_{95}$. In the scans of $I_{p}$, at fixed $B_{T}$ and shape, the island overlap region width at higher $q_{95}$ during the ELMing phase is larger than the overlap width during phases with lower $q_{95}$ in the resonance window for complete ELM suppression. The ELM suppression sensitivity to the $q$-profile is more complicated than simply achieving sufficient width of the island overlap region.

The detailed physics understanding of why the maximum ELM size correlates, for fixed $q_{95}$, with the width of the island overlap region or the fractional loss of short field lines from a vacuum fields analysis remains for future work. In addition, other experimental ordering parameters such as $\beta_{\text {ped }}$ do a good job of separating the experimental data, but the physical implications of the other parameters have not yet been explored. Finally, the vacuum island overlap width does not take into account the response of the plasma to the applied fields, including the possible screening or amplification of the vacuum fields ${ }^{68,69}$ by the plasma response. Without knowledge of the screening or amplification response profile, the present data analysis cannot conclusively reject the possibility that the changes in particle transport leading to ELM suppression occur farther out in the plasma nearer to the pedestal than indicated by this vacuum fields analysis. The physics underlying the difference between ELM mitigation (moderate size reduction and frequency increase) due to RMPs and full ELM suppression must also be determined by including the self-consistent fields within the plasma, but this analysis is beyond the scope of this paper. The fully selfconsistent simulations will likely identify other parameters that order the maximum ELM size data at least as well as the vacuum island overlap width, and will also show the physics mechanisms leading to that ordering. However, until those fully self-consistent simulations are available, the model of a minimum vacuum island overlap width required to achieve full ELM suppression provides an initial criterion by which to estimate the required currents in candidate coil designs for future tokamaks including ITER. This then allows the evaluation of the additional consequences of applying perturbations of the estimated required size on other aspects of plasma operation to begin.

\section{ACKNOWLEDGMENTS}

This work was performed under the auspices of the U.S. Department of Energy by Lawrence Livermore National Laboratory in part under Contract No. W-7405-ENG-48 and in part under Contract No. DE-AC52-07NA27344, and under Contract Nos. DE-FC02-04ER54698, DE-FG0207ER54917, and DE-FG02-05ER54809.

${ }^{1}$ G. Federici, P. Andrew, P. Barabaschi, J. Brooks, R. Doerner, A. Grier, A. Herrmann, G. Janeschitz, K. Krieger, A. Kukushkin, A. Loarte, R. Neu, G. Saibene, M. Shimada, G. Strohmayer, and M. Sugihara, J. Nucl. Mater. 313-316, 11 (2003).

${ }^{2}$ S. C. Cowley, H. Wilson, O. Hurricane, and B. Fong, Plasma Phys. Controlled Fusion 45, A31 (2003); H. R. Wilson and S. C. Cowley, Phys. Rev. Lett. 92, 175006 (2004).

${ }^{3}$ A. W. Leonard, J. A. Boedo, M. E. Fenstermacher, R. J. Groebner, M. Goth, C. J. Lasnier, M. A. Mahdavi, T. H. Osborne, D. L. Rudakov, T. W. Petrie, and J. G. Watkins, J. Nucl. Mater. 313-316, 768 (2003).

${ }^{4}$ ITER Physics Basis Editors, ITER Physics Expert Group Chairs and CoChairs, and ITER Joint Central Team and Physics Integration Unit, "ITER Physics Basics," Nucl. Fusion 39, 2137 (1999); 47, S1 (2007).

${ }^{5}$ A. Zhitlukhin, N. Klimov, I. Landman, J. Linke, A. Loarte, M. Merola, V. Podkovyrov, G. Federici, B. Bazylev, S. Pestchanyi, V. Safronov, T. Hirai, V. Maynashev, V. Levashov, and A. Muzichenko, J. Nucl. Mater. 363365, 301 (2007).

${ }^{6}$ H. Zohm, Plasma Phys. Controlled Fusion 38, 105 (1996).

${ }^{7}$ M. E. Fenstermacher, A. W. Leonard, P. B. Snyder, J. A. Boedo, N. H. Brooks, R. J. Colchin, D. S. Gray, R. J. Groebner, M. Goth, E. Hollman, C. J. Lasnier, T. H. Osborne, T. W. Petrie, D. L. Rudakov, H. Takahashi, J. G. Watkins, L. Zeng, and the DIII-D Team, Plasma Phys. Controlled Fusion 45, 1597 (2003).

${ }^{8}$ O. Sauter, C. Angioni, and Y. R. Lin-Liu, Phys. Plasmas 6, 2834 (1999). ${ }^{9}$ T. E. Evans, M. E. Fenstermacher, R. A. Moyer, T. H. Osborne, J. G. Watkins, P. Gohil, I. Joseph, M. J. Schaffer, L. R. Baylor, M. Bécoulet, J. A. Boedo, K. H. Burrell, J. S. deGrassie, K. H. Finken, T. Jernigan, M. W. Jakubowski, C. J. Lasnier, M. Lehnen, A. W. Leonard, J. Lonnroth, E. Nardon, V. Parail, O. Schmitz, B. Unterberg, and W. P. West, Nucl. Fusion 48, 024002 (2008).

${ }^{10}$ T. H. Osborne, P. B. Snyder, T. E. Evans, R. A. Moyer, M. J. Schaffer, K. H. Burrell, R. J. Groebner, A. W. Leonard, D. M. Thomas, G. Wang, and L. Zeng, "Edge stability analysis and pedestal and ELM characteristics in I-coil ELM suppressed discharges on DIII-D," in Proceedings of the 32nd EPS Conference on Controlled Fusion and Plasma Physics, Tarragona, 
Spain (European Physical Society, Lausanne, 2005), Paper P-4.012, Vol. 29C, http://eps2005.ciemat.es/papers/html/contents.htm.

${ }^{11}$ K. H. Burrell, T. E. Evans, E. J. Doyle, M. E. Fenstermacher, R. J. Groebner, A. W. Leonard, R. A. Moyer, T. H. Osborne, M. J. Schaffer, P. B. Snyder, P. R. Thomas, W. P. West, J. A. Boedo, A. M. Garofalo, P. Gohil, G. L. Jackson, R. J. La Haye, C. J. Lasnier, H. Reimerdes, T. L. Rhodes, J. T. Scoville, W. M. Solomon, D. M. Thomas, G. Wang, J. G. Watkins, and L. Zeng, Plasma Phys. Controlled Fusion 47, B37 (2005).

${ }^{12}$ T. E. Evans, K. H. Burrell, M. E. Fenstermacher, R. A. Moyer, T. H. Osborne, M. J. Schaffer, W. P. West, L. W. Yan, J. A. Boedo, E. J. Doyle, G. L. Jackson, I. Jospeph, C. J. Lasnier, A. W. Leonard, T. L. Rhodes, P. R. Thomas, J. G. Watkins, and L. Zeng, Phys. Plasmas 13, 056121 (2006). ${ }^{13}$ R. A. Moyer, K. H. Burrell, T. E. Evans, M. E. Fenstermacher,P. Gohil, I. Jospeph, T. H. Osborne, M. J. Schaffer, P. B. Snyder, J. G. Watkins, L. R. Baylor, M. Bécoulet, J. A. Boedo, N. H. Brooks, E. J. Doyle, K.-H. Finken, P. Garbet, M. Groth, J. Harris, E. M. Hollmann, G. L. Jackson, M. Jakubowski, T. C. Jernigan, S. Kasilov, C. J. Lasnier, A. W. Leonard, M. Lehnen, J. Lönnroth, E. Nardon, V. Parail, G. D. Porter, T. L. Rhodes, D. L. Rudakov, A. Runov, O. Schmitz, R. Schneider, D. M. Thomas, P. Thomas, G. Wang, W. P. West, L. Yan, J. H. Yu, and L. Zeng, in Proceedings of the 49th IAEA Fusion Energy Conference, Chengdu, China (2006), http://www-pub.iaea.org/MTCD/Meetings/FEC2006/ex_9-3.pdf.

${ }^{14}$ M. E. Fenstermacher, T. E. Evans, R. A. Moyer, G. D. Porter, J. A. Boedo, K. H. Burrell, M. Groth, I. Joseph, T. H. Osborne, and J. G. Watkins, J. Nucl. Mater. 363-365, 476 (2007).

${ }^{15}$ T. E. Evans, R. A. Moyer, P. R. Thomas, J. G. Watkins, T. H. Osborne, J. A. Boedo, E. J. Doyle, M. E. Fenstermacher, K. H. Finken, R. J. Groebner, M. Groth, J. H. Harris, R. J. La Haye, C. J. Lasnier, S. Masuzaki, N. Ohyabu, D. G. Pretty, T. L. Rhodes, H. Reimerdes, D. L. Rudakov, M. J. Schaffer, G. Wang, and L. Zeng, Phys. Rev. Lett. 92, 235003 (2004).

${ }^{16}$ T. E. Evans and R. A. Moyer, J. Nucl. Mater. 337-339, 691 (2005).

${ }^{17}$ R. A. Moyer, T. E. Evans, T. H. Osborne, P. R. Thomas, M. Bécoulet, J. Harris, K.-H. Finken, J. A. Boedo, E. J. Doyle, M. E. Fenstermacher, P. Gohil, R. J. Groebner, M. Groth, G. L. Jackson, R. J. La Haye, C. J. Lasnier, A. W. Leonard, G. R. McKee, H. Reimerdes, T. L. Rhodes, D. L. Rudakov, M. J. Schaffer, P. B. Snyder, M. R. Wade, G. Wang, J. G. Watkins, W. P. West, and L. Zeng, Phys. Plasmas 12, 056119 (2005).

${ }^{18}$ T. E. Evans, R. A. Moyer, J. G. Watkins, T. H. Osborne, P. R. Thomas, M. Bécoulet, J. A. Boedo, E. J. Doyle, M. E. Fenstermacher, K.-H. Finken, R. J. Groebner, M. Groth, J. H. Harris, G. L. Jackson, R. J. La Haye, C. J. Lasnier, S. Masuzaki, N. Ohyabu, D. G. Pretty, H. Reimerdes, T. L. Rhodes, D. L. Rudakov, M. J. Schaffer, M. R. Wade, G. Wang, W. P. West, and L. Zeng, Nucl. Fusion 45, 595 (2005).

${ }^{19}$ T. E. Evans, R. A. Moyer, K. H. Burrell, M. E. Fenstermacher, I. Joseph, A. W. Leonard, T. H. Osborne, G. D. Porter, M. J. Schaffer, P. B. Snyder, P. R. Thomas, J. G. Watkins, and W. P. West, Nat. Phys. 2, 419 (2006).

${ }^{20}$ P. T. Lang, G. D. Conway, T. Eich, L. Fattorini, O. Gruber, S. Günter, L. D. Horton, S. Kalvin, A. Kallenbach, M. Kaufmann, G. Kocsis, A. Lorenz, M. E. Manso, M. Maraschek, V. Mertens, J. Neuhauser, I. Nunes, W. Schneider, W. Suttrop, H. Urano, and the ASDEX Upgrade Team, Nucl. Fusion 44, 665 (2004).

${ }^{21}$ A. W. Degeling, Y. R. Martin, J. B. Lister, L. Villard, V. N. Dokouka, V. E. Lukash, and R. R. Khayrutdinov, Plasma Phys. Controlled Fusion 45, 1637 (2003).

${ }^{22}$ P. T. Lang, A. W. Degeling, J. B. Lister, Y. R. Martin, P. J. McCarthy, A. C. C. Sips, W. Suttrop, G. D. Conway, L. Fattorini, O. Gruber, L. D. Horton, A. Herrmann, M. E. Manso, M. Maraschek, V. Mertens, A. Mück, W. Schneider, C. Sihler, W. Treutterer, H. Zohm, and the ASDEX Upgrade Team, Plasma Phys. Controlled Fusion 46, L31 (2004).

${ }^{23}$ Y. Kamada, R. Yoshino, Y. Neyatani, M. Sato, S. Tokuda, M. Azumi, S. Takeji, K. Ushigusa, T. Fukuda, M. Mori, T. Takizuka, and the JT-60U Team, Plasma Phys. Controlled Fusion 38, 1387 (1996).

${ }^{24}$ N. Oyama, Y. Sakamoto, A. Isayama, M. Takechi, P. Gohil, L. L. Lao, P. B. Snyder, T. Fujita, S. Ide, Y. Kamada, Y. Miura, T. Oikawa, T. Suzuki, H. Takenaga, K. Toi, and the JT-60 Team, Nucl. Fusion 45, 871 (2005).

${ }^{25}$ J. Stober, O. Gruber, A. Kallenbach, V. Mertens, F. Ryter, A. Stabler, W. Suttrop, W. Treutterer, and the ASDEX Upgrade Team, Plasma Phys. Controlled Fusion 42, A211 (2000).

${ }^{26}$ R. Maingi, K. Tritz, E. D. Fredrickson, J. E. Menard, S. A. Sabbagh, D. Stutman, M. G. Bell, R. E. Bell, C. E. Bush, D. A. Gates, D. W. Johnson, R. Kaita, S. M. Kaye, H. W. Kugel, B. P. LeBlanc, D. Mueller, R. Raman, A. L. Roquemore, and V. A. Soukhanovskii, Nucl. Fusion 45, 264 (2005). ${ }^{27}$ R. Maingi, C. E. Bush, E. D. Fredrickson, D. A. Gates, S. M. Kaye, B. P. LeBlanc, J. E. Menard, H. Meyer, D. Mueller, N. Nishino, A. L. Ro- quemore, S. A. Sabbagh, K. Tritz, S. J. Zweben, M. G. Bell, R. E. Bell, T. Biewer, J. A. Boedo, D. W. Johnson, R. Kaita, H. W. Kugel, R. J. Maqueda, T. Munsat, R. Raman, V. A. Soukhanovskii, T. Stevenson, and D. Stutman, Nucl. Fusion 45, 1066 (2005).

${ }^{28}$ G. Saibene, P. J. Lomas, R. Sartori, A. Loarte, J. Stober, Y. Andrew, S. A. Arshad, G. D. Conway, E. de la Luna, K. Günther, L. C. Ingesson, M. A. H. Kempensaars, A. Korotkov, H. R. Koslowski, J. S. Lönnroth, D. C. McDonald, A. Meigs, P. Monier-Garbet, V. Parail, C. P. Perez, F. G. Rimini, S. Sharapov, and P. R. Thomas, Nucl. Fusion 45, 297 (2005).

${ }^{29}$ Y. Takase, R. L. Boivin, F. Bombada, P. T. Bonoli, C. Christensen, C. Fiore, D. Garnier, J. A. Goetz, S. N. Golovato, R. Granetz, M. Greenwald, S. F. Horne, A. Hubbard, I. H. Hutchinson, J. Irby, B. LaBombard, B. Lipschultz, E. Marmar, M. May, A. Mazurenko, G. McCracken, P. O'Shea, M. Porkolab, J. Reardon, J. Rice, C. Rost, J. Schachter, J. A. Snipes, P. Stek, J. Terry, R. Watterson, B. Welch, and S. Wolfe, Phys. Plasmas 4, 1647 (1997).

${ }^{30}$ T. Shoji, H. Tamai, Y. Miura, M. Mori, H. Ogawa, A. W. Leonard, T. Jensen, A. W. Hyatt, A. M. Howald, G. Fuchs, N. Ohyabu, N. Asakura, T. Fujita, M. Shimada, S. Tsuji, H. Maeda, H. Aikawa, K. Hoshino, S. Kasai, T. Kawakami, H. Kawashima, M. Maeno, T. Matsuda, T. Ogawa, T. Seike, N. Suzuki, K. Uehara, T. Yamanoto, T. Yamauchi, T. Hamano, K. Hasegawa, A. Honda, M. Kazawa, Y. Kashiwa, K. Kituchi, H. Okano, E. Sato, N. Seki, T. Shibata, T. Shiina, S. Suzuki, T. Tani, T. Tokutake, Y. Tomiyama, and T. Yamasoto, J. Nucl. Mater. 196-198, 296 (1992).

${ }^{31}$ K. Kamiya, H. Kimura, H. Ogawa, H. Kawashima, K. Tsuzuki, M. Sato, Y. Miura, and JFT-2M Group, Nucl. Fusion 43, 1214 (2003).

${ }^{32}$ S. J. Fielding, R. J. Buttery, A. R. Field, P. B. Jones, H. Meyer, M. Valovic, and H. R. Wilson, "ELM Control in COMPASS-D," in Proceedings of the 28th European Physical Society Conference on Controlled Fusion and Plasma Physics, Madeira, ECA (European Physical Society, Mulhouse, Cedex, France, 2001), Vol. 25A, p. 1825.

${ }^{33}$ T. Ozeki, M. S. Chu, L. L. Lao, T. S. Taylor, M. S. Chance, S. Kinoshita, K. H. Burrell, and R. D. Stambaugh, Nucl. Fusion 30, 1425 (1990).

${ }^{34}$ K. H. Burrell, M. E. Austin, D. P. Brennan, J. C. Deboo, E. J. Doyle, C. Fenzi, C. Fuchs, P. Gohil, C. M. Greenfield, R. J. Groebner, L. L. Lao, T. C. Luce, M. A. Makowski, G. R. McKee, R. A. Moyer, C. C. Petty, M. Porkolab, C. L. Rettig, T. L. Rhodes, J. C. Rost, B. W. Stallard, E. J. Strait, E. J. Synakowski, M. R. Wade, J. G. Watkins, and W. P. West, Phys. Plasmas 8, 2153 (2001)

${ }^{35}$ K. H. Burrell, W. P. West, E. J. Doyle, M. E. Austin, J. S. deGrassie, P. Gohil, C. M. Greenfield, R. J. Groebner, R. Jayakumar, D. H. Kaplan, L. L. Lao, A. W. Leonard, M. A. Makowski, G. R. McKee, W. M. Solomon, D. M. Thomas, T. L. Rhodes, M. R. Wade, G. Wang, J. G. Watkins, and L. Zeng, Plasma Phys. Controlled Fusion 46, A165 (2004).

${ }^{36}$ W. Suttrop, G. D. Conway, L. Fattorini, L. D. Horton, T. Kurki-Suonio, C. F. Maggi, M. Maraschek, H. Meister, R. Neu, Th. Pütterich, M. Reich, A. C. C. Sips, and the ASDEX Upgrade Team, Plasma Phys. Controlled Fusion 46, A151 (2004).

${ }^{37}$ Y. Sakamoto, H. Shirai, T. Fujita, S. Ide, T. Takizuka, N. Oyama, and Y. Kamada, Plasma Phys. Controlled Fusion 46, A299 (2004).

${ }^{38}$ W. P. West, K. H. Burrell, T. A. Casper, E. J. Doyle, P. B. Snyder, P. Gohil, L. L. Lao, C. J. Lasnier, A. W. Leonard, M. F. F. Nave, T. H. Osborne, D. M. Thomas, G. Wang, and L. Zeng, Nucl. Fusion 45, 1708 (2005).

${ }^{39}$ J. S. deGrassie, N. Ohyabu, N. H. Brooks, K. W. Gentle, R. Bengston, R. Bravenec, W. Hodge, T. Kochanski, K. Nelin, P. Phillips, T. Price, B. Richards, C. Ritz, W. Rowan, S. B. Kim, C. Klepper, S. Levinson, K. Leung, J. Porter, and J. Snipes, J. Nucl. Mater. 128-129, 266 (1984).

${ }^{40}$ T. E. Evans, J. S. deGrassie, G. L. Jackson, N. Ohyabu, A. J. Wootton, K. W. Gentle, W. L. Hodge, S. C. McCool, P. E. Phillips, T. L. Rhodes, B. Richards, Ch. P. Ritz, W. L. Rowan, F. Karger, and G. Haas, J. Nucl. Mater. 145-147, 812 (1987).

${ }^{41}$ S. C. McCool, A. J. Wooton, A. Y. Aydemir, R. D. Bengtson, J. A. Boedo, R. V. Bravenec, D. L. Brower, J. S. deGrassie, T. E. Evans, S. P. Fan, J. C. Forster, M. S. Foster, K. W. Gentle, Y. X. He, R. L. Hickock, G. L. Jackson, S. K. Kim, M. Kotschenreuther, N. C. Luhmann, Jr., W. H. Miner, Jr., T. L. Rhodes, B. Richards, C. P. Ritz, D. W. Ross, W. L. Rowan, P. M. Schoch, B. A. Smith, J. C. Wiley, X. H. Yu, and S. B. Zheng, Nucl. Fusion 29, 547 (1989).

${ }^{42}$ A. J. Wooton, J. Nucl. Mater. 176-177, 77 (1990).

${ }^{43}$ S. C. McCool, A. J. Wooton, M. Kottschenreuther, A. Y. Aydemir, R. V. Bravenec, J. S. deGrassie, T. E. Evans, R. L. Hickok, B. Richards, W. L. Rowan, and P. M. Schoch, Nucl. Fusion 30, 167 (1990).

${ }^{44} \mathrm{Ph}$. Ghendrih, A. Grossman, and H. Capes, Plasma Phys. Controlled Fusion 38, 1653 (1996) 
${ }^{45} \mathrm{Ph}$. Ghendrih, M. Bécoulet, L. Colas, A. Grosman, R. Guirlet, J. Gunn, T. Loarer, A. Azéroual, V. Basiuk, B. Beaumont, A. Bécoulet, P. Beyer, S. Brémond, J. Bucalossi, H. Capes, Y. Corre, L. Costanzo, C. De Michelis, P. Devynck, S. Féron, C. Friant, X. Garbet, R. Giannella, C. Grisolia, W. Hess, J. Hogan, L. Ladurelle, F. Laugier, G. Martin, M. Mattioli, B. Meslin, P. Monier-Garbet, D. Moulin, F. Nguyen, J.-Y. Pascal, A.-L. Pecquet, B. Pégourié, R. Reichle, F. Saint-Laurent, J.-C. Vallet, M. Zabiégo, and Tore Supra Team Nucl. Fusion 42, 1221 (2002).

${ }^{46}$ K. H. Finken, G. Fuchs, B. Glesen, M. Haßler, R. Kock, G. Mank, A. Nicolai, A. Rogister, M. Z. Tokar, R. Van Nieuwenhove, G. Van Oost, and G. H. Wolf, J. Nucl. Mater. 220-222, 448 (1995).

${ }^{47}$ K. H. Finken, S. S. Abdullaev, W. Biel, M. F. M. de Bock, C. Busch, E. Farshi, M. von Hellermann, G. M. D. Hogeweij, M. Jakubowski, R. Jaspers, H. R. Koslowski, A. Kraemer-Flecken, A. Lazaros, M. Lehnen, Y. Liang, A. Nicolai, O. Schmitz, B. Unterberg, E. Westerhof, R. Wolf, O. Zimmermann, M. de Baar, G. Bertschinger, S. Brezinsek, I. G. J. Classen, A. J. H. Donné, H. G. Esser, H. Gerhauser, B. Giesen, D. Harting, J. A. Hoekzema, P. W. Huettemann, S. Jachmich, K. Jakubowska, D. Kalupin, F. Kelly, Y. Kikuchi, A. Kirschner, R. Koch, M. Korten, A. Kreter, J. Krom, U. Kruezi, A. Litnovsky, X. Loosen, N. J. Lopes Cardozo, A. Lyssoivan, O. Marchuk, Ph. Martens, A. Messiaen, O. Neubauer, V. Phillips, A. Pospieszczyk, D. Reiser, D. Reiter, A. L. Rogister, T. Van Rompuy, A. Savtchkov, U. Samm, R. P. Schorn, F. C. Schueller, B. Schweer, G. Sergienko, K. H. G. Telesca, M. Tokar, G. Van Oost, R. Uhlemann, G. Van Wassenhove, R. Weynants, S. Wiesen, and Y. Xu, Plasma Phys. Controlled Fusion 46, B143 (2004).

${ }^{48}$ R. C. Wolf, W. Biel, M. F. M. de Bock, K. H. Finken, S. Günter, G. M. D. Hogeweij, S. Jachmich, M. W. Jakubowski, R. J. E. Jaspers, A. KramerFlecken, H. R. Koslowski, M. Lehnen, Y. Liang, B. Unterberg, S. K. Varshney, M. von Hellermann, Q. Yu, O. Zimmermann, S. S. Abdullaev, A. J. H. Donné, U. Samm, B. Schweer, M. Tokar, E. Westerhof, and the TEXTOR Team, Nucl. Fusion 45, 1700 (2005).

${ }^{49}$ M. W. Jakubowski, S. S. Abdullaev, K. H. Finken, and the TEXTOR Team, Nucl. Fusion 44, S1 (2004).

${ }^{50}$ K. H. Finken, Nucl. Fusion 46, S107 (2006).

${ }^{51}$ Y. Liang, H. R. Koslowski, P. R. Thomas, E. Nardon, B. Alper, P. Andrew, G. Arnoux, Y. Baranov, M. Bécoulet, M. Beurskens, T. Biewer, M. Bigi, K. Crombe, E. De La Luna, P. de Vries, W. Fundamenski, S. Gerasimov, C. Giroud, M. P. Gryaznevich, N. Hawkes, S. Hotchin, D. Howell, S. Jachmich, V. Kiptily, L. Moreira, V. Parail, S. D. Pinches, E. Rachlew, and O. Zimmerman, Phys. Rev. Lett. 98, 265004 (2007).

${ }^{52}$ P. B. Snyder, H. R. Wilson, J. R. Ferron, L. L. Lao, A. W. Leonard, D.
Mossessian, M. Murakami, T. H. Osborne, A. D. Turnbull, and X. Q. Xu, Nucl. Fusion 44, 320 (2004).

${ }^{53}$ M. J. Schaffer, J. E. Menard, M. P. Aldan, J. M. Bialek, T. E. Evans, and R. A. Moyer, Nucl. Fusion 48, 024004 (2008).

${ }^{54}$ B. V. Chirikov, Phys. Rep. 52, 263 (1979).

${ }^{55}$ M. J. Schaffer and R. J. La Haye, private communication (2007).

${ }^{56}$ H. R. Wilson, P. B. Snyder, G. T. A. Huysmans, and R. L. Miller, Phys. Plasmas 9, 1277 (2002).

${ }^{57}$ P. B. Snyder, H. R. Wilson, and X. Q. Xu, Phys. Plasmas 12, 056115 (2005); P. B. Snyder, H. R. Wilson, J. R. Ferron, L. L. Lao, A. W. Leonard, T. H. Osborne, A. D. Turnbull, D. Mossessian, M. Murakami, and X. Q. Xu, ibid. 9, 2037 (2002).

${ }^{58}$ P. B. Snyder, K. H. Burrell, H. R. Wilson, M. S. Chu, M. E. Fenstermacher, A. W. Leonard, R. A. Moyer, T. H. Osborne, M. Umansky, W. P. West, and X. Q. Xu, Nucl. Fusion 47, 961 (2007).

${ }^{59}$ T. H. Osborne, P. B. Snyder, K. H. Burrell, T. E. Evans, M. E. Fenstermacher, A. W. Leonard, R. A. Moyer, M. J. Schaffer, and W. P. West, "Edge stability of stationary ELM-suppressed regimes on DIII-D," Plasma Phys. Controlled Fusion (in press).

${ }^{60}$ A. W. Leonard, T. A. Casper, R. J. Groebner, T. H. Osborne, P. B. Snyder, and D. M. Thomas, Nucl. Fusion 47, 552 (2007).

${ }^{61}$ G. D. Porter, J. Moller, M. Brown, and C. Lasnier, Phys. Plasmas 5, 1410 (1998).

${ }^{62}$ L. L. Lao, H. E. St. John, Q. Peng, J. R. Ferron, E. J. Strait, T. S. Taylor, W. H. Meyer, C. Zhang, K. I. You, Fusion Sci. Technol. 48, 968 (2005); L. L. Lao, H. E. St. John, R. D. Stambaugh, A. G. Kellmann, and W. Pfeiffer, Nucl. Fusion 25, 1611 (1985).

${ }^{63}$ J. L. Luxon, M. J. Schaffer, G. L. Jackson, J. A. Leuer, A. Nagy, J. T. Scoville, and E. J. Strait, Nucl. Fusion 43, 1813 (2003).

${ }^{64}$ T. E. Evans, R. A. Moyer, and P. Monet, Phys. Plasmas 3, 4957 (2002).

${ }^{65}$ T. E. Evans, J. S. deGrassie, G. L. Jackson et al., Proceedings of the 14th EPS Conference on Controlled Fusion and Plasma Physics, Madrid, Spain (European Physical Society, Mulhouse, Cedex, France, 1987), Vol. 11D, p. 770.

${ }^{66}$ S. Takamura, N. Ohnishi, H. Yourada, and T. Okuda, Phys. Fluids 30, 144 (1987).

${ }^{67}$ R. J. Hawryluk and members of ITER Design Review WG1 Design Requirements and Physics Objectives Sub-group on ELM and RWM Control, private communication (2007).

${ }^{68}$ R. Fitzpatrick, Phys. Plasmas 5, 3325 (1998).

${ }^{69}$ A. Cole and R. Fitzpatrick, Phys. Plasmas 13, 032503 (2006). 